\title{
Asset pricing with return extrapolation ${ }^{\star}$
}

Lawrence J. Jin ${ }^{a, *}$ and Pengfei Sui ${ }^{b}$

a Division of the Humanities and Social Sciences, California Institute of Technology, 1200 E. California Blvd., Pasadena, CA 91125, USA

${ }^{b}$ School of Management and Economics and Shenzhen Finance Institute, the Chinese University of Hong Kong, Shenzhen, China

\section{ABSTRACT}

We present a new model of asset prices in which a representative agent has extrapolative beliefs about stock market returns and Epstein-Zin preferences. The model quantitatively explains facts about asset prices, return expectations, and cash-flow expectations. When the agent's beliefs about stock market returns are calibrated to survey expectations of investors, the model generates excess volatility and predictability of stock market returns, a high equity premium, a low and stable risk-free rate, and a low correlation between stock market returns and consumption growth. Moreover, the model has implications for expectations about future cash flows that are consistent with empirical findings.

JEL classification: G02, G12

Keywords: Expectations, Extrapolation, Asset Prices

\footnotetext{
*We are grateful to David Hirshleifer (the editor), an anonymous referee, Nicholas Barberis, John Campbell, Stefano Cassella, Alexander Chinco, Ricardo De la O, Michael Ewens, Cary Frydman, Robin Greenwood, Philip Hoffman, Jonathan Ingersoll, Dana Kiku, Theresa Kuchler, Jiacui Li, Lars Lochstoer, Sean Myers, Cameron Peng, Andrei Shleifer, Jessica Wachter, Baolian Wang, Jianfeng Yu, and seminar participants at Caltech, Maastricht University, Tilburg University, the University of California, Irvine, the University of Southern California, the Young Economists Symposium at Yale, the Caltech Junior Faculty Behavioral Finance Conference, the Finance Down Under Conference, CICF, the SFS Cavalcade North America meeting, the NBER Behavioral Finance meeting, the NBER Summer Institute Asset Pricing meeting, and the American Finance Association Annual Meeting for very helpful comments.

* Corresponding author at: Division of the Humanities and Social Sciences, California Institute of Technology, 1200 E. California Blvd., Pasadena, CA 91125, USA. Phone: 626-395-4558. Fax: 626-793-4681.

E-mail addresses: jin@caltech.edu (L. Jin), psui@cuhk.edu.cn (P. Sui)
} 


\section{Introduction}

In financial economics, there is growing interest in "return extrapolation," the idea that investors' beliefs about an asset's future return are a positive function of the asset's recent past returns. Models with return extrapolation have two appealing features. First, they are consistent with survey evidence on the beliefs of real-world investors. ${ }^{1}$ Second, they show promise in matching important asset pricing facts, such as volatility and predictability in the aggregate market, momentum and reversals in the cross-section, and bubbles (Hong and Stein, 1999; Barberis, 2018; Barberis, Greenwood, Jin, and Shleifer, 2015, 2018; Liao, Peng, and Zhu, 2021). To study the asset pricing implications of return extrapolation, a researcher must also make an assumption about investor preferences. The most prominent preference specification in recent research on asset prices is arguably Epstein-Zin utility.

In this paper, we propose a new model of aggregate stock market prices based on return extrapolation and Epstein-Zin preferences. The goal of the paper is to provide a new behavioral model that simultaneously explains facts about asset prices, return expectations, and cash-flow expectations. We show that, when a representative agent's beliefs about stock market returns are calibrated to match survey expectations of real-world investors, return extrapolation and Epstein-Zin preferences together allow the model to quantitatively explain facts about stock market prices. Moreover, we find that return extrapolation has direct implications for expectations about future cash flows that are consistent with recent empirical findings.

We consider a Lucas economy in continuous time with a representative agent. The Lucas tree is a claim to an aggregate consumption process which follows a geometric Brownian motion. There are two tradeable assets in the economy: the stock market and an instantaneous riskless asset. The stock market is a claim to an aggregate dividend process whose growth rate is positively correlated with consumption growth. The riskless asset is in zero net supply with its interest rate determined in equilibrium. The representative agent has extrapolative beliefs and Epstein-Zin preferences. She perceives that the expected growth rate of stock market prices is governed by a switching process

\footnotetext{
${ }^{1}$ Vissing-Jorgensen (2004), Bacchetta, Mertens, and van Wincoop (2009), Amromin and Sharpe (2013), Greenwood and Shleifer (2014), Kuchler and Zafar (2019), and Da, Huang, and Jin (2021) examine survey data and find that many individual and institutional investors have extrapolative expectations: they believe that an asset's price will continue rising in value after a sequence of high past returns, and continue falling in value after a sequence of low past returns.
} 
between two regimes. If the recent price growth of the stock market has been high, the agent thinks it is likely that a high-mean price growth regime is generating prices and therefore forecasts high price growth in the future. Conversely, if the recent price growth has been low, the agent thinks that it is likely that a low-mean price growth regime is generating prices and therefore forecasts low price growth in the future.

We calibrate the agent's beliefs about stock market returns to match the survey expectations of investors studied in Greenwood and Shleifer (2014). Specifically, we set the belief-based parameters so that, in a regression of the agent's expectations about future stock market returns on past 12month returns, the model produces a regression coefficient and a $t$-statistic that match the empirical estimates from surveys. Our parameter choice also allows the agent's beliefs to match the survey evidence on the relative weight investors put on recent versus distant past returns when forming beliefs about future returns. With the agent's beliefs disciplined by survey data in this way, the model quantitatively matches important facts about the aggregate stock market: it generates significant excess volatility and predictability of stock market returns, a high equity premium, a low and stable interest rate, as well as a low correlation between stock market returns and consumption growth.

We now explain the model's implications, starting with excess volatility. The model generates average return volatility of $24.8 \%$ for the stock market, much higher than the volatility of dividend growth, which is set to $11 \%$. The excess volatility of stock market returns comes from the interaction between return extrapolation and Epstein-Zin preferences. Suppose that the stock market has had high past returns. Return extrapolation then leads the agent to forecast high future returns. Under Epstein-Zin preferences, and consistent with the prior literature, we set risk aversion to be higher than the reciprocal of the elasticity of intertemporal substitution, giving rise to a strong substitution effect. As such, the agent's forecast of high future returns leads her to push up the current price significantly, generating excess volatility. ${ }^{2}$

The mechanism described above for generating excess volatility, together with a strong degree of mean reversion in the agent's expectations about stock market returns, produces the predictability of stock market returns from the price-dividend ratio that we observe in the data. The agent's

\footnotetext{
${ }^{2}$ As we further discuss in Section 3, the model's fit to the data is significantly diminished when we replace EpsteinZin preferences with power utility while keeping all other parameter values fixed; for example, the model-implied return volatility decreases significantly, from $24.8 \%$ to $13.0 \%$.
} 
beliefs mean-revert for two reasons. First, by assumption, the agent believes that the expected growth rate of stock market prices tends to switch over time from one regime to the other; as a result, she perceives that her expectations about stock market returns will mean-revert. Second, the agent's return expectations actually mean-revert faster than she thinks they will: when the agent thinks that the future price growth is high, future price growth tends to be low endogenously, causing her return expectations to decrease at a pace that exceeds what she anticipated. As a result, following periods with a high price-dividend ratio - this is when the agent's expectation about future returns is high - the agent's return expectation tends to revert back to its mean, giving rise to low subsequent returns and hence the predictability of stock market returns using the price-dividend ratio.

Next, we turn to the model's implications for the equity premium. When measured as the rational expectation of stock market returns in excess of the interest rate, the model generates an average equity premium of $7.36 \% .^{3}$ Two factors contribute to the high equity premium. First, the agent's risk aversion causes her to demand a substantial equity premium in the face of excess return volatility. Second, return extrapolation gives rise to perceived persistence of the aggregate dividend process, which, under Epstein-Zin preferences, is significantly priced, pushing up the equity premium. Note that both return extrapolation and Epstein-Zin preferences are important for generating a high equity premium: in the absence of return extrapolation, Epstein-Zin preferences with i.i.d. dividend and consumption growth give rise to a very small equity premium of $0.84 \%$; in the absence of Epstein-Zin preferences - that is, with power utility - return extrapolation alone generates an equity premium of only $1.93 \%$.

Finally, the model generates low interest rate volatility and a low correlation between stock market returns and consumption growth. In the model, the agent forms different beliefs about the dividend growth of the stock market and about aggregate consumption growth. Here, we assume that the bias in the agent's beliefs about consumption growth derives only from the bias in her beliefs about dividend growth. Given the low observed correlation between consumption growth and dividend growth, the derived bias in the agent's beliefs about consumption growth is small, consistent with the fact that there is no direct empirical evidence for extrapolative beliefs about consumption growth. The agent's approximately correct beliefs about consumption growth allow

\footnotetext{
${ }^{3}$ When measured as the rational expectation of log excess returns, the average equity premium is $4.27 \%$.
} 
the model to generate low interest rate volatility. They also imply that the agent's beliefs about stock market returns, which comove strongly with the agent's beliefs about dividend growth, are not significantly affected by fluctuations in consumption growth, giving rise to a low correlation between stock market returns and consumption growth.

Although our model is based on return extrapolation, it also has direct implications for cashflow expectations. When the past price growth of the stock market has been high, this has a positive effect not only on the agent's beliefs about future returns, but also on her beliefs about future dividend growth; indeed, her expectations about dividend growth rise more quickly than her expectations about future returns. ${ }^{4}$ Given this, a Campbell-Shiller decomposition using the agent's subjective expectations about stock market returns and dividend growth shows that changes in subjective expectations about future dividend growth explain $110 \%$ of the variance of the pricedividend ratio, while changes in subjective return expectations explain $-10 \%$ of the variance of the price-dividend ratio. This quantitatively matches the recent empirical findings of De la $\mathrm{O}$ and Myers (2021), who show that changes in investors' subjective expectations of future dividend growth explain the majority of stock market movements. In this way, our model simultaneously accounts for the empirical findings of Greenwood and Shleifer (2014) on return expectations and the empirical findings of De la O and Myers (2021) on cash-flow expectations.

Our model also points to some challenges for return extrapolation: when calibrated to the survey expectations data, the model predicts a persistence of the price-dividend ratio that is lower than its empirical value. To match the empirical persistence of the price-dividend ratio, investors need to form beliefs about future returns based on many years of past returns. However, the available survey evidence suggests that they focus on just the past year or two. Section 4 discusses a potential resolution of this issue.

After presenting the model, we compare it to alternative models of the aggregate stock market, including models with cash flow extrapolation and models with rational expectations. Our model is developed in a Lucas economy with a representative agent. This allows for a quantitative comparison between our model and many alternative models of the stock market. We discuss their distinct implications in Section 4.

Our paper adds to a growing theoretical literature that studies the role of return extrapolation in

\footnotetext{
${ }^{4}$ We provide a detailed explanation of this finding in Sections 2 and 3 and in Appendix D.
} 
explaining asset pricing facts. Early models, such as Cutler, Poterba, and Summers (1990) and De Long, Shleifer, Summers, and Waldmann (1990), highlight the conceptual importance of return extrapolation, but they are not designed to match asset pricing facts quantitatively. Barberis, Greenwood, Jin, and Shleifer (2015) present a dynamic consumption-based model that tries to make sense of both survey expectations and aggregate stock market prices. However, the simplifying assumptions in their model make it difficult to evaluate the model's fit with the empirical facts. ${ }^{5}$ Our model overcomes this limitation and allows for a quantitative comparison with the data. Moreover, our model makes a methodological contribution to the literature: it provides a numerical procedure for solving asset pricing models that assume biased beliefs about endogenous equilibrium outcomes.

Our model is related to, but fundamentally different from, several recent models that use biased beliefs to quantitatively match empirical facts about the stock market. The models of Choi and Mertens (2013), Hirshleifer, Li, and Yu (2015), and Nagel and Xu (2021) assume a representative agent with extrapolative beliefs about fundamentals, in which the agent's expectation of future cash-flow growth depends positively on a weighted average of past cash-flow growth. Our model, on the other hand, assumes return extrapolation. Both assumptions, fundamental extrapolation and return extrapolation, are supported by survey expectations of real-world investors, and both types of models aim to make sense of facts about asset prices. As we explain in Section 4, while our model assumes only return extrapolation, it also produces patterns of investor beliefs that are consistent with fundamental extrapolation. However, the models that assume fundamental extrapolation typically do not give rise to return extrapolation; for example, the model of Nagel and $\mathrm{Xu}$ (2021) is not able to match the observed positive correlation between return expectations and past 12-month returns. This contrast highlights a key difference between these two types of models. Adam, Marcet, and Beutel (2017) present a model that explains the data on both return expectations and asset prices. The mechanism in their model is quite distinct from the mechanism in our model. In their model, agents have fully rational beliefs about future dividend growth, but do not observe the exact mapping between dividends and stock prices. As such, their model generates extrapolative beliefs about returns but nonextrapolative beliefs about dividend growth.

\footnotetext{
${ }^{5}$ For instance, their model adopts a framework with constant absolute risk aversion (CARA) preferences and a constant interest rate. Under these assumptions, many ratio-based quantities that we study in asset pricing (e.g., the price-dividend ratio) do not have well-defined distributions in the model and therefore do not have properties that match what we observe in the data.
} 
In our model, however, beliefs about returns and beliefs about dividend growth are closely tied to each other and both extrapolative; therefore, our model makes sense of both facts about return expectations (Greenwood and Shleifer, 2014) and facts about cash-flow expectations (De la O and Myers, 2021; Nagel and Xu, 2021). More broadly, our model is related to asset pricing models under biased or nontraditional beliefs in the form of natural expectations (Fuster, Hebert, and Laibson, 2011), diagnostic expectations (Bordalo, Gennaioli, and Shleifer, 2018), memory retrieval (Wachter and Kahana, 2020, 2021), and investor overconfidence (Daniel, Hirshleifer, and Subrahmanyam, 1998; Daniel, Klos, and Rottke, 2021).

The paper proceeds as follows. In Section 2, we lay out the basic elements of the model and characterize its solution. In Section 3, we parameterize the model and examine its implications for asset prices, return expectations, and cash-flow expectations. Section 4 discusses some additional aspects of our analysis. Section 5 concludes and suggests directions for future research. Additional details are in the Appendix.

\section{The Model}

In this section, we first describe the model setup. We then characterize the model's solution and briefly discuss equilibrium quantities that are important for understanding the implications of the model.

\subsection{Model setup}

Asset space. We consider an infinite-horizon Lucas economy in continuous time with a representative agent. The Lucas tree is a claim to an aggregate consumption process that follows a geometric Brownian motion

$$
d C_{t} / C_{t}=g_{C} d t+\sigma_{C} d \omega_{t}^{C}
$$

We denote the price of the Lucas tree at time $t$ as $P_{t}^{C}$.

Besides the Lucas tree, there are two other tradeable assets in the economy; they are the main focus of our analysis. The first asset is the stock market, which is a claim to an aggregate dividend 
process given by

$$
d D_{t} / D_{t}=g_{D} d t+\sigma_{D} d \omega_{t}^{D}
$$

we denote the price of the stock market at time $t$ as $P_{t}^{D} \cdot{ }^{6}$ Both $\omega_{t}^{D}$ and $\omega_{t}^{C}$ are standard Brownian motions. We assume that the instantaneous correlation between $d D_{t}$ and $d C_{t}$ is $\rho>0: \mathbb{E}_{t}\left[d \omega_{t}^{D}\right.$. $\left.d \omega_{t}^{C}\right]=\rho d t$. The second asset is an instantaneous riskless asset. This asset is in zero net supply, and its interest rate $r_{t}$ is determined in equilibrium.

Agent's preferences. We follow Epstein and Zin $(1989,1991)$ and assume that the agent has recursive intertemporal utility

$$
U_{t}=\left[\left(1-e^{-\delta d t}\right) C_{t}^{1-\psi} d t+e^{-\delta d t}\left(\mathbb{E}_{t}^{e}\left[\tilde{U}_{t+d t}^{1-\gamma}\right]\right)^{(1-\psi) /(1-\gamma)}\right]^{1 /(1-\psi)}
$$

where $\delta$ is the subjective discount rate, $\gamma>0$ is the coefficient of relative risk aversion, and $\psi>0$ is the reciprocal of the elasticity of intertemporal substitution. When $\psi$ equals $\gamma,(3)$ reduces to power utility. As discussed in the Introduction, Epstein-Zin preferences, rather than power utility, allow the model to generate quantitatively realistic implications; we discuss this point further in Section 3. The superscript " $e$ " denotes extrapolative expectations: the certainty equivalent in (3) is computed under the representative agent's subjective beliefs, which, as we specify later, incorporate the notion of return extrapolation.

The subjective Euler equation, or first-order condition, is

$$
\mathbb{E}_{t}^{e}\left[e^{-\delta(1-\gamma) d t /(1-\psi)}\left(\frac{\tilde{C}_{t+d t}}{C_{t}}\right)^{-\psi(1-\gamma) /(1-\psi)} \tilde{M}_{t+d t}^{(\psi-\gamma) /(1-\psi)} \tilde{R}_{j, t+d t}\right]=1
$$

Here, $\tilde{M}_{t+d t}$ is the gross return on the optimal portfolio held by the agent from time $t$ to time $t+d t$. In a Lucas economy with a representative agent, the optimal portfolio in equilibrium is the Lucas

\footnotetext{
${ }^{6}$ Since the aggregate consumption process in the model is exogenous, the dividend payment from the stock market does not further affect consumption. As a result, we can think of the stock market as an asset in zero net supply with a shadow price determined in equilibrium. This is a common assumption adopted by other consumption-based models such as Campbell and Cochrane (1999) and Barberis, Huang, and Santos (2001).
} 
tree itself, and therefore

$$
\tilde{M}_{t+d t}=\frac{\tilde{P}_{t+d t}^{C}+\tilde{C}_{t} d t}{P_{t}^{C}}=\frac{\tilde{P}_{t+d t}^{C}+\tilde{C}_{t+d t} d t}{P_{t}^{C}}+o(d t) .
$$

On the other hand, $\tilde{R}_{j, t+d t}$ is the gross return on any tradeable asset $j$ in the market from time $t$ to time $t+d t$; as mentioned above, the two tradeable assets we focus on are the stock market and the riskless asset.

Agent's beliefs. We now turn to the key part of the model: the representative agent's beliefs about stock market returns. According to surveys, real-world investors' expectations about asset returns depend positively on the assets' recent past returns (Vissing-Jorgensen, 2004; Bacchetta, Mertens, and van Wincoop, 2009; Amromin and Sharpe, 2013; Greenwood and Shleifer, 2014; Kuchler and Zafar, 2019; Da, Huang, and Jin, 2021). One way to capture this notion of return extrapolation is through a regime-switching model. Specifically, we suppose that the agent believes that the expected growth rate of stock market prices is governed by $(1-\theta) g_{D}+\theta \tilde{\mu}_{S, t}$, where the parameter $\theta(0 \leq \theta \leq 1)$ controls the extent to which the agent's beliefs are extrapolative: setting $\theta$ to zero makes the agent's beliefs fully rational. More important, $\tilde{\mu}_{S, t}$ in the agent's beliefs is a latent variable that switches between a high value $\mu_{H}$ in a high-mean price growth regime $H$ and a low value $\mu_{L}\left(\mu_{L}<\mu_{H}\right)$ in a low-mean price growth regime $L$ with the following transition $\operatorname{matrix}^{7}$

$$
\begin{aligned}
& \tilde{\mu}_{S, t+d t}=\mu_{H} \quad \tilde{\mu}_{S, t+d t}=\mu_{L}
\end{aligned}
$$

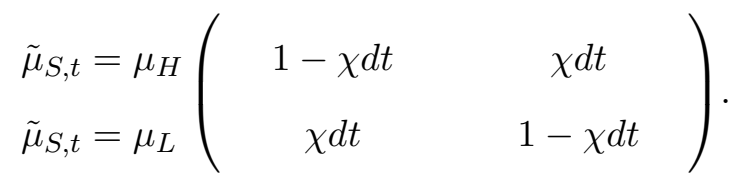

Here, $\chi$ is the intensity perceived by the agent for the transitions of regime between $H$ and $L$.

Given this regime-switching model - this is a perceived model, not the true model - if the recent stock market price growth has been high, the agent subjectively believes it is likely that the highmean price growth regime is generating prices and therefore forecasts high price growth in the future. Conversely, if the recent price growth has been low, the agent believes it is likely that the low-mean price growth regime is generating prices and therefore forecasts low price growth in

\footnotetext{
${ }^{7}$ The models of Barberis, Shleifer, and Vishny (1998), Veronesi (1999), and Jin (2015) also adopt a regime-switching learning structure.
} 
the future. Formally, at each point in time, the agent computes the expected value of the latent variable $\tilde{\mu}_{S, t}$ given the history of past price growth: $S_{t} \equiv \mathbb{E}\left[\tilde{\mu}_{S, t} \mid \mathcal{F}_{t}^{P}\right]$. That is, she applies optimal filtering theory (see, for example, Lipster and Shiryaev, 2001) and obtains

$$
\begin{aligned}
d S_{t} & =\chi\left[\left(\mu_{H}-S_{t}\right)+\left(\mu_{L}-S_{t}\right)\right] d t+\left(\sigma_{P, t}^{D}\right)^{-1} \theta\left(\mu_{H}-S_{t}\right)\left(S_{t}-\mu_{L}\right) d \omega_{t}^{e} \\
& \equiv \mu_{S}^{e}\left(S_{t}\right) d t+\sigma_{S}\left(S_{t}\right) d \omega_{t}^{e},
\end{aligned}
$$

where $d \omega_{t}^{e} \equiv\left[d P_{t}^{D} / P_{t}^{D}-(1-\theta) g_{D} d t-\theta S_{t} d t\right] / \sigma_{P, t}^{D}$ is a standard Brownian innovation term from the agent's perspective. As a result, she perceives the evolution of the stock market price $P_{t}^{D}$ to be

$$
d P_{t}^{D} / P_{t}^{D}=\mu_{P}^{D, e}\left(S_{t}\right) d t+\sigma_{P}^{D}\left(S_{t}\right) d \omega_{t}^{e},
$$

where

$$
\mu_{P}^{D, e}\left(S_{t}\right)=(1-\theta) g_{D}+\theta S_{t}
$$

The agent's expectation about price growth $\mu_{P}^{D, e}\left(S_{t}\right)$ is therefore a linear combination of a rational component $g_{D}$ and a behavioral component $S_{t}$; hereafter we call $S_{t}$ the "sentiment variable."

In summary, the evolution of sentiment in (7) captures return extrapolation: high past price growth $d P_{t}^{D} / P_{t}^{D}$ pushes up the perceived shock $d \omega_{t}^{e}$, which leads the agent to raise her expectation of the sentiment variable $S_{t}$, causing her expectation about future price growth $\mu_{P}^{D, e}\left(S_{t}\right)$ to rise. $^{8}$

Although the subjective evolution of sentiment (7) is derived through optimal learning, the representative agent, it should be emphasized, does not hold rational expectations. With rational expectations, the agent will realize in the long run that the regime-switching model (6) is incorrect: she can look at the historical distribution of $d \omega_{t}^{e}$ and realize that it does not fit a normal distribution with a mean of zero and a variance of $d t$. Instead, the behavioral agent in our model always believes that the regime-switching model is correct. In reality, it is possible that investors in the market learn over time that their mental model is incorrect. At the same time, new investors who hold

\footnotetext{
${ }^{8}$ To capture return extrapolation, there are a number of ways to specify the evolution of $S_{t}$. We derive $S_{t}$ from a regime-switching model, in part because such a learning model captures base rate neglect, an important consequence of the representativeness heuristic (Tversky and Kahneman, 1974). To see this, note that the perceived regimes or states, $H$ and $L$, are not part of the true states of the economy. As a result, assigning positive probabilities to these regimes reflect the bias that the agent neglects the zero base rate associated with such regimes. Moreover, a regime-switching model allows us to bound $S_{t}$ by a finite range $\left(\mu_{L}, \mu_{H}\right)$, reducing the analytical difficulty of solving the model.
} 
extrapolative beliefs could continuously enter the market. The stable belief system in (6) is an analytically convenient way to capture these dynamics. Alternatively, if Eqs. (6) and (7) represent the true data-generating process, then the agent does hold rational expectations. In that case, the model becomes a fully rational model with incomplete information. ${ }^{9}$ We discuss the predictions of such a model in Section 4.

So far, we have been focusing on the agent's beliefs about stock market prices. These beliefs have direct implications for the agent's beliefs about dividend growth. If we write the perceived dividend process as

$$
d D_{t} / D_{t}=g_{D}^{e}\left(S_{t}\right) d t+\sigma_{D} d \omega_{t}^{e}
$$

the agent's expectation about dividend growth $g_{D}^{e}\left(S_{t}\right)$ is directly tied to her expectation about stock market price growth $\mu_{P}^{D, e}\left(S_{t}\right)$. To see this connection, we first observe that all the ratio-based quantities in our model (e.g., the price-dividend ratio of the stock market) are a function of the sentiment variable $S_{t}$; we define $f\left(S_{t}\right) \equiv P_{t}^{D} / D_{t}$. We then apply Ito's lemma to both sides of the equation $f\left(S_{t}\right)=P_{t}^{D} / D_{t}$ and match terms to obtain

$$
g_{D}^{e}\left(S_{t}\right)=\underbrace{(1-\theta) g_{D}+\theta S_{t}}_{\text {expectation of price growth }} \underbrace{-\left(f^{\prime} / f\right) \mu_{S}^{e}\left(S_{t}\right)}_{\text {expectation of sentiment evolution }} \underbrace{+\sigma_{D}^{2}-\sigma_{P}^{D}\left(S_{t}\right) \sigma_{D}-\frac{1}{2}\left(f^{\prime \prime} / f\right)\left(\sigma_{S}\left(S_{t}\right)\right)^{2}}_{\text {Ito correction terms }},
$$

where

$$
\sigma_{P}^{D}\left(S_{t}\right)=\frac{\sigma_{D}+\sqrt{\sigma_{D}^{2}+4 \theta\left(\mu_{H}-S_{t}\right)\left(S_{t}-\mu_{L}\right)\left(f^{\prime} / f\right)}}{2}>\sigma_{D} .
$$

Eq. (11) highlights an "expectations transmission mechanism": it says that the agent's expectation about dividend growth equals the sum of her expectation about stock market price growth, her expectation about how the price-dividend ratio evolves with respect to changes in sentiment, and the Ito correction terms that are related to the agent's risk aversion and the volatility of dividend growth, price growth, and changes in sentiment. In this way, the agent's expectation about price

\footnotetext{
${ }^{9}$ Information is incomplete in the sense that the agent does not directly observe the latent variable $\tilde{\mu}_{S, t}$ in $(6)$.
} 
growth affects her expectation about dividend growth. It is worth noting that our model assumes return extrapolation and then derives the agent's beliefs about dividend growth. In reality, however, it is possible that investors form beliefs about dividend growth, which then imply beliefs about future returns. It is also possible that beliefs about future dividend growth and beliefs about future returns are formed separately. We leave a careful study of investors' belief formation process for future research.

With the parameter values we specify later, Eq. (11) indicates that the agent's expectation about dividend growth is more responsive to changes in sentiment than her expectation about price growth. To see why, first note that, under Epstein-Zin preferences, we set risk aversion to be higher than the reciprocal of the elasticity of intertemporal substitution, giving rise to a strong intertemporal substitution effect. As a result, when the past price growth has been high, the agent's forecast of high future price growth leads her to push up the current price-dividend ratio, making it an increasing function of sentiment. Furthermore, under the regime-switching model, the agent perceives sentiment to be mean-reverting: $\mu_{S}^{e}\left(S_{t}\right)$ in $(7)$ is a decreasing function of $S_{t}$. This indicates that the agent also perceives the price-dividend ratio to be mean-reverting. Together, these two conditions - the price-dividend ratio is an increasing function of sentiment and is perceived to be mean-reverting - imply that the agent anticipates that the price-dividend ratio will decline from a high value when she expects high future price growth. That is, when the agent expects high future price growth, her expectation about dividend growth rises more quickly than her expectation about future price growth. This implication is consistent with recent empirical findings of $\mathrm{De}$ la $\mathrm{O}$ and Myers (2021); Section 3 and Appendix D provide a formal analysis. Moreover, Section 3 analyzes survey expectations data to provide direct support for Eqs. (8) to (11).

To complete the description of the model, we need to specify the agent's beliefs about consumption growth. To do this, first note that, with a local correlation of $\rho$ between consumption growth and dividend growth, we can rewrite the true aggregate consumption process in (1) as

$$
d C_{t} / C_{t}=g_{C} d t+\sigma_{C}\left(\rho d \omega_{t}^{D}+\sqrt{1-\rho^{2}} d \omega_{t}^{\perp}\right)
$$

where $\omega_{t}^{\perp}$ is a Brownian motion that is locally uncorrelated with $\omega_{t}^{D}$, the Brownian shock on 
dividends. We then write the agent's perceived consumption process as

$$
d C_{t} / C_{t}=g_{C}^{e}\left(S_{t}\right) d t+\sigma_{C}\left(\rho d \omega_{t}^{e}+\sqrt{1-\rho^{2}} d \omega_{t}^{\perp}\right)
$$

That is, we replace the true Brownian shock on dividends $d \omega_{t}^{D}$ in (13) by the agent's perceived Brownian shock $d \omega_{t}^{e}$ and incorporate the difference in consumption growth caused by these two Brownian shocks, $\rho \sigma_{C}\left(d \omega_{t}^{e}-d \omega_{t}^{D}\right)$, into $g_{C}^{e}\left(S_{t}\right)$, the agent's subjective expectation about consumption growth. Conceptually, this amounts to assuming that the bias in the agent's beliefs about consumption growth comes only from the bias in her beliefs about dividend growth. ${ }^{10}$ In doing so, we derive the agent's expectation about consumption growth to be

$$
g_{C}^{e}\left(S_{t}\right)=g_{C}+\rho \sigma_{C} \sigma_{D}^{-1}\left(g_{D}^{e}\left(S_{t}\right)-g_{D}\right)
$$

Note from Eqs. (11) and (15) that the agent's perceived consumption process is not exogenously assumed. Instead, it is endogenously determined, together with the agent's beliefs about price growth and dividend growth; as we will discuss in Section 2.2 and Appendix A, these expectations need to satisfy two subjective Euler equations specified in Eqs. (A.1) and (A.6).

Empirically, the correlation between consumption growth and dividend growth is low- $\rho$ is positive but low - and consumption growth is much less volatile than dividend growth $-\sigma_{C}$ is much smaller than $\sigma_{D}$. As a result, (15) implies that the bias in the agent's expectation about consumption growth, namely, the difference between $g_{C}^{e}\left(S_{t}\right)$ and $g_{C}$, is small. This implication is consistent with the fact that there is no direct evidence that investors have extrapolative beliefs about consumption growth. ${ }^{11}$ Moreover, the agent's approximately correct beliefs about consumption growth allow the model to generate low interest rate volatility and a low correlation between consumption growth and stock market returns, both of which are consistent with the data (Campbell, 2003; Hansen and Singleton, 1982, 1983).

\footnotetext{
${ }^{10}$ For any alternative assumption, one needs to explain why the agent has incorrect beliefs about consumption above and beyond her incorrect beliefs about dividends.

${ }^{11}$ Consistent with the way we model the agent's expectations about dividend growth and consumption growth, Kuchler and Zafar (2019) find that survey expectations are "asset-specific": respondents who become pessimistic about their employment situation after experiencing unemployment are not pessimistic about other economic outcomes, such as stock prices or interest rates. Similarly, Huang (2019) finds that investors who become optimistic about an industry's future returns after having positive prior investment experience in the industry do not invest heavily in an unrelated industry.
} 


\subsection{Model solution and equilibrium quantities}

The subjective Euler equation in (4) shows that, when pricing the stock market, both the stock market return and the return from holding the Lucas tree are part of the pricing kernel. This has two implications. First, both the price-dividend ratio $f\left(S_{t}\right)=P_{t}^{D} / D_{t}$ and the wealth-consumption ratio $P_{t}^{C} / C_{t}$ are functions of the sentiment variable $S_{t}$; we define $l\left(S_{t}\right) \equiv P_{t}^{C} / C_{t}$. Second, the two functions $f$ and $l$ are interrelated through Euler equations, so they need to be solved simultaneously. Specifically, by using the Euler equation to price the stock market and the Lucas tree - that is, by setting $\tilde{R}_{j, t+d t}$ in (4) to the gross return on the stock market and to the gross return on the Lucas tree, respectively - we obtain two ordinary differential equations that jointly determine functions $f$ and $l$. Appendix A provides a detailed derivation of these two differential equations; see Eqs. (A.1) and (A.6). Appendix C further provides the numerical procedure that solves them.

With the model solution at hand, we derive the expressions of several equilibrium quantities that are important for understanding the model's implications. We start with the equilibrium interest rate, a quantity that is important for computing excess returns and the equity premium. By using the Euler equation in (4) to price the riskless asset - by setting $\tilde{R}_{j, t+d t}$ to the gross return on the riskless asset $1+r_{t} d t$-we obtain

$$
r_{t}=\frac{1-\gamma}{1-\psi} \delta+\gamma g_{C}^{e}-\frac{\gamma(\gamma+1)}{2} \sigma_{C}^{2}-\frac{\psi-\gamma}{1-\psi} \times\left[\begin{array}{c}
\left(\mu_{S}^{e}-\gamma \rho \sigma_{C} \sigma_{S}\right)\left(l^{\prime} / l\right)+\frac{1}{2} \sigma_{S}^{2}\left(l^{\prime \prime} / l\right) \\
+\frac{2 \psi-\gamma-1}{2(1-\psi)} \sigma_{S}^{2}\left(l^{\prime} / l\right)^{2}+l^{-1}
\end{array}\right]
$$

The interest rate is linked to the agent's time preferences, her subjective expectation about consumption growth, precautionary saving, as well as how the wealth-consumption ratio $P_{t}^{C} / C_{t}$ responds to changes in sentiment. ${ }^{12}$

Next, we compute the agent's expectation about future stock market returns, which can be compared to non-price data such as survey expectations. From Eqs. (8) and (9), the gross return on the stock market from time $t$ to time $t+d t$ is

$$
R_{t+d t}^{D} \equiv\left(P_{t+d t}^{D}+D_{t+d t} d t\right) / P_{t}^{D}=1+\left[(1-\theta) g_{D}+\theta S_{t}+f^{-1}\right] d t+\sigma_{P}^{D} d \omega_{t}^{e} .
$$

\footnotetext{
${ }^{12}$ When $\theta=0$, the agent's beliefs are fully rational, and $r=\delta+\psi g_{C}-\frac{\gamma(\psi+1)}{2} \sigma_{C}^{2}$.
} 
Therefore, the agent's time- $t$ expectation about the (annualized) excess return of the stock market from $t$ to $t+d t$ is

$$
\mathbb{E}_{t}^{e}\left[\hat{r}_{t+d t}^{D, e}\right] \equiv \mathbb{E}_{t}^{e}\left[\left(R_{t+d t}^{D}-1\right) / d t-r_{t}\right]=(1-\theta) g_{D}+\theta S_{t}+f^{-1}-r_{t}
$$

To study the implications of the model for some quantities - for example, the predictability of stock market returns - we follow the empirical literature by looking at the log excess return on the stock market instead of the raw return. From Eqs. (17) and (18), the log excess return from time $t$ to time $t+d t$ is

$$
\begin{aligned}
r_{t+d t}^{D, e} d t & \equiv \ell \ln \left(P_{t+d t}^{D}+D_{t+d t} d t\right)-\ell \operatorname{n}\left(P_{t}^{D}\right)-r_{t} d t \\
& =\left[(1-\theta) g_{D}+\theta S_{t}+f^{-1}-\frac{1}{2}\left(\sigma_{P}^{D}\right)^{2}-r_{t}\right] d t+\sigma_{P}^{D} d \omega_{t}^{e} .
\end{aligned}
$$

Moreover, the agent's subjective expectation about the log excess return is

$$
\mathbb{E}_{t}^{e}\left[r_{t+d t}^{D, e}\right]=(1-\theta) g_{D}+\theta S_{t}+f^{-1}-\frac{1}{2}\left(\sigma_{P}^{D}\right)^{2}-r_{t}
$$

When we assess the model's implications for the equity premium, we compute the (objectively measured) rational expectation about future stock market returns. We compare (2) with (10) and obtain a relation between the true and perceived Brownian shocks

$$
d \omega_{t}^{e}=d \omega_{t}^{D}-\left(g_{D}^{e}\left(S_{t}\right)-g_{D}\right) d t / \sigma_{D}
$$

We then substitute (21) into (19) and derive

$$
r_{t+d t}^{D, e} d t=\left[(1-\theta) g_{D}+\theta S_{t}+f^{-1}-\sigma_{D}^{-1} \sigma_{P}^{D}\left(g_{D}^{e}-g_{D}\right)-\frac{1}{2}\left(\sigma_{P}^{D}\right)^{2}-r_{t}\right] d t+\sigma_{P}^{D} d \omega_{t}^{D}
$$

As a result, the rational expectation about the log excess return on the stock market is

$$
\mathbb{E}_{t}\left[r_{t+d t}^{D, e}\right]=(1-\theta) g_{D}+\theta S_{t}+f^{-1}-\sigma_{D}^{-1} \sigma_{P}^{D}\left(g_{D}^{e}-g_{D}\right)-\frac{1}{2}\left(\sigma_{P}^{D}\right)^{2}-r_{t} .
$$


The rational expectation about the excess return on the stock market is

$$
\mathbb{E}_{t}\left[\hat{r}_{t+d t}^{D, e}\right]=(1-\theta) g_{D}+\theta S_{t}+f^{-1}-\sigma_{D}^{-1} \sigma_{P}^{D}\left(g_{D}^{e}-g_{D}\right)-r_{t}
$$

Finally, two things are worth noting. First, one can think of Eq. (21) as derived by an outside econometrician, who knows that the true dividend process follows Eq. (2) and that the behavioral agent thinks the process follows Eq. (10); the behavioral agent does not need to be aware of Eq. (21). Second, all the ratio-based quantities in this model such as the agent's expectation about stock market returns and the interest rate are a function of the sentiment variable $S_{t}$. Therefore, a statistical assessment of the model's fit with the empirical facts requires knowing the steady-state distribution for the sentiment variable $S_{t}$ as objectively measured by an outside econometrician. We leave the derivation of this steady-state distribution to Appendix B.

\section{Model Implications}

In this section, we examine the implications of the model. We begin by setting the benchmark values for the model parameters. In particular, we discuss how to calibrate the agent's beliefs to match the survey evidence documented in Greenwood and Shleifer (2014). We then discuss the model's implications for asset prices and for cash-flow expectations.

\subsection{Model parameterization}

There are three types of parameters: asset parameters, utility parameters, and belief parameters. For the asset parameters, we set $g_{C}=1.91 \%, g_{D}=2.45 \%, \sigma_{C}=3.8 \%, \sigma_{D}=11 \%$, and $\rho=0.2$. These values are consistent with those used in Campbell and Cochrane (1999), Barberis, Huang, and Santos (2001), and Beeler and Campbell (2012). ${ }^{13}$ For the utility parameters, we set $\gamma$, the coefficient of relative risk aversion, to ten. The long-run risks literature typically assigns a value of ten or below for $\gamma \cdot{ }^{14}$ For $\psi$, the reciprocal of the elasticity of intertemporal substitution, there is a wide range of estimates in the asset pricing literature. The majority of previous papers suggest

\footnotetext{
${ }^{13}$ The parameter values for $g_{C}$ and $g_{D}$ are set such that both $\ell \operatorname{n}(C)$ and $\ell \operatorname{n}(D)$ grow, on average, at an annual rate of $1.84 \%$; this rate is also used in Barberis, Huang, and Santos (2001).

${ }^{14} \mathrm{~A}$ value of ten for $\gamma$ is also the maximum magnitude that Mehra and Prescott (1985) find reasonable.
} 
that $\psi$ should be lower than one, but some papers argue the opposite. ${ }^{15}$ Given this, we set $\psi$ to 0.9 , a value that implies an elasticity of intertemporal substitution slightly above one. As discussed in Section 4, our model's implications are quantitatively robust even with an elasticity of intertemporal substitution significantly lower than one. Finally, for $\delta$, the subjective discount rate, we assign a value of $2 \%$.

We now turn to the belief parameters. We set $\mu_{H}$ and $\mu_{L}$, the mean price growth in the high and low regimes, to $12.5 \%$ and $-12.5 \%$, respectively. As we will see later in this section, the probability of the agent's price growth expectations approaching the boundaries of $\mu_{H}$ and $\mu_{L}$ is approximately zero. As a result, the model's implications are not very sensitive to the choice of $\mu_{H}$ and $\mu_{L}$.

Next, we focus on $\theta$, the parameter that controls the extent to which the representative agent is behavioral, and $\chi$, the perceived transition intensity between the high- and low-mean price growth regimes. Given that our model assumes a representative agent, the agent's beliefs should be compared to both beliefs of individual investors and those of professional forecasters. For beliefs of individual investors, we look at three out of six surveys studied in Greenwood and Shleifer (2014): the Gallup survey, the American Association of Individual Investors survey (AA), and the Investors' Intelligence newsletter expectations survey (II). For beliefs of professional forecasters, we examine economists' return expectations from the Federal Reserve Bank of Philadelphia's Livingston survey.

We calibrate the agent's beliefs to match investor expectations from the four surveys mentioned above. Specifically, we set $\theta=0.5$ and $\chi=0.2$ so that the agent's beliefs match survey data along two dimensions: one measures the overall extent to which investor expectations respond to past returns; the other measures the weight investors put on distant past returns relative to recent past returns when forming beliefs about future returns. We now examine these two dimensions in detail. First, to measure the overall extent to which investor expectations respond to past returns, Greenwood and Shleifer (2014) regress the average investor expectations about the future stock market return on past 12-month cumulative returns

$$
\text { Expectation }_{t}=a+b \cdot R_{t-12 \rightarrow t}^{D}+\varepsilon_{t} .
$$

For a 16-year sample of data from the Gallup survey, the regression coefficient is $11.6 \%$ with a

\footnotetext{
${ }^{15}$ See Beeler and Campbell (2012) for a discussion of this point.
} 
$t$-statistic of 8.8 ; for a 29 -year sample of data from AA, the regression coefficient is $3.4 \%$ with a $t$-statistic of 4.1 ; for a 53 -year sample of data from II, the regression coefficient is $8.0 \%$ with a $t$-statistic of 6.2 ; and for a 40-year sample of data from Livingston, the regression coefficient is $-7.1 \%$ with a $t$-statistic of -1.9 .

\section{[Place Table 1 about here]}

Using model simulations, Table 1 reports the regression coefficient, its $t$-statistic, the intercept, and the $R$-squared for a similar regression of the agent's time- $t$ expectation about the future stock market return on the past 12 -month cumulative return

$$
\mathbb{E}_{t}^{e}\left[\left(d P_{t}^{D}+D_{t} d t\right) /\left(P_{t}^{D} d t\right)\right]=a+b \cdot R_{t-12 \rightarrow t}^{D}+\varepsilon_{t},
$$

over a sample of 15 or 50 years. Table 1 shows that, for a 15-year simulated sample, the regression coefficient is $2.0 \%$ with a Newey-West adjusted $t$-statistic of 8.6. Hartzmark and Solomon (2021) suggest that investors do not take the dividend yield into account when calculating returns. If we replace the dependent variable in $(26)$ by $\mathbb{E}_{t}^{e}\left[d P_{t}^{D} /\left(P_{t}^{D} d t\right)\right]$, the agent's expectation of price growth, then a 15-year simulated sample gives a regression coefficient of $3.5 \%$ with a $t$-statistic of 8.7 . These results indicate that, in a regression of the agent's return expectations on past 12-month returns, our model produces a regression coefficient and a $t$-statistic that lie between the empirical estimates from survey expectations of individual investors (Gallup, AA, and II) and the empirical estimates from survey expectations of professional forecasters (Livingston).

The values of $\theta$ and $\chi$ are also chosen to match the agent's beliefs with the survey evidence on the relative weight of recent versus distant past returns in determining investors' return expectations. Specifically, Greenwood and Shleifer (2014) estimate the following nonlinear least squares regression

$$
\text { Expectation }_{t}=a+b \cdot \sum_{j=1}^{n} w_{j}(\phi) R_{(t-j \Delta t) \rightarrow(t-(j-1) \Delta t)}^{D}+\varepsilon_{t},
$$


from surveys; $R_{(t-j \Delta t) \rightarrow(t-(j-1) \Delta t)}^{D}$ is the past stock market return from time $t-j \Delta t$ to $t-(j-1) \Delta t$ with $\Delta t=1 / 4$ (one quarter); and $w_{j}(\phi) \equiv \phi^{j} / \sum_{l=1}^{n} \phi^{l}$. In Eq. (27), each past realized return is assigned a weight. The weight decreases exponentially the further back we go into the past, and the 
coefficient $\phi$ in the weights $\left\{w_{j}(\phi)\right\}_{j=1}^{n}$ measures the speed of this exponential decline. For Gallup, the estimate of $\phi$ is 0.78 ; for AA, the estimate of $\phi$ is 0.38 ; for II, the estimate of $\phi$ is 0.51 ; and for Livingston, the estimate of $\phi$ is 0.92 .

\section{[Place Table 2 about here]}

To estimate $\phi$ from the model, we run the following nonlinear least squares regression, one that is analogous to $(27)$,

$$
\mathbb{E}_{t}^{e}\left[\left(d P_{t}^{D}+D_{t} d t\right) /\left(P_{t}^{D} d t\right)\right]=a+b \cdot \sum_{j=1}^{n} w_{j}(\phi) R_{(t-j \Delta t) \rightarrow(t-(j-1) \Delta t)}^{D}+\varepsilon_{t},
$$

using model simulations. Here $w_{j}(\phi)=\phi^{j} / \sum_{l=1}^{n} \phi^{l}$ is the same as in (27), $\Delta t=1 / 4$, and $n$ $=200$ (50 years). Table 2 reports the parameter $\phi$, the intercept $a$, the regression coefficient $b$, and the $R$-squared. Each reported value is averaged over 100 trials, and each trial represents a regression using monthly data simulated from the model over 10,000 years. Table 2 shows that the model-implied $\phi$ is 0.89 , which means that a monthly return three years ago is weighted about $25 \%$ as much as the most recent return; that is, the agent looks back a couple of years when forming beliefs about future returns. The model-implied $\phi$ lies between the empirical estimates using survey expectations of individual investors (Gallup, AA, and II) and the empirical estimate using survey expectations of professional forecasters (Livingston). In this sense, the values of $\theta$ and $\chi$ allow the agent's beliefs to match the survey evidence on the relative weight of recent versus distant past returns in determining investors' return expectations.

\section{[Place Table 3 about here]}

Table 3 summarizes all the parameter values. In Section 4, we provide a comparative statics analysis to examine the sensitivity of the model's implications to changes in some of these parameter values.

\subsection{Model implications for asset prices}

In this section, we study the model's implications for asset prices. We begin by examining the long-run properties of stock market prices and returns. Table 4 reports the model's predictions for 
six important moments, and compares them side by side with the empirical values. In general, the model matches the facts: it generates significant excess volatility, a high equity premium, a Sharpe ratio similar to the empirical value, an interest rate that has a low level and low volatility, and a price-dividend ratio whose average level is close to the empirical one.

\section{[Place Table 4 about here]}

Return volatility. As explained in Section 1, the model generates significant excess volatility from the interaction between return extrapolation and Epstein-Zin preferences. If recent past returns are high, the agent thinks that future returns will also be high. With our choice of parameter values for Epstein-Zin preferences, the coefficient of relative risk aversion $\gamma$ is higher than the reciprocal of the elasticity of intertemporal substitution $\psi$; a strong intertemporal substitution effect arises. As such, the agent's forecast of high future returns leads her to push up prices, increasing current returns further. ${ }^{16}$ This interaction between beliefs and preferences is quantitatively important. In the absence of return extrapolation, Epstein-Zin preferences with i.i.d. dividend growth and consumption growth do not lead to any excess volatility. In the absence of Epstein-Zin preferencesthat is, setting both $\psi$ and $\gamma$ to ten while keeping all the other parameter values unchanged - return extrapolation alone leads to average return volatility of $13.0 \%$, which implies much less excess volatility compared to the data. ${ }^{17}$

Equity premium. The model also generates a significant equity premium: when measured as the rational expectation of excess returns $\mathbb{E}\left[\left(d P_{t}^{D}+D_{t} d t\right) /\left(P_{t}^{D} d t\right)-r_{t}\right]$, the average equity premium is $7.36 \%$; when measured as the rational expectation of log excess returns, it is $4.27 \%$. To understand this implication, we first note that the model produces a substantial equity premium perceived by the agent - this is, the agent's subjective equity premium averaged across the distribution of sentiment. When measured as the subjective expectation of excess returns $\mathbb{E}^{e}\left[\left(d P_{t}^{D}+D_{t} d t\right) /\left(P_{t}^{D} d t\right)-r_{t}\right]$,

\footnotetext{
${ }^{16}$ Higher current returns - caused by the agent's optimistic beliefs about future returns - cause the agent's beliefs to become even more optimistic; a feedback loop emerges. In general, there is a danger that this feedback loop could "explode." Nonetheless, in the model, we assume the agent believes that the expected growth rate of stock market prices tends to switch over time from one regime to the other; she therefore believes that her optimism will decline in the future. As a result, the cumulative impact of the feedback loop on the agent's expectations and asset prices is finite; the model remains stable. Models like Cutler, Poterba, and Summers (1990) and Barberis, Greenwood, Jin, and Shleifer (2015) instead introduce fully rational agents to counteract the behavioral agents and preserve equilibrium.

${ }^{17}$ Moreover, when Epstein-Zin preferences reduce to power utility, the equity premium, measured as the rational expectation of $\log$ excess returns, falls from $4.27 \%$ to $1.08 \%$, a level much lower than the empirical value. In greater detail, Li and Liu (2020) show that, when combined with power utility, return extrapolation does not lead to quantitatively realistic implications for asset prices.
} 
the perceived equity premium is $4.30 \%$; when measured as the subjective expectation of log excess returns, it is $1.21 \%$. Two factors contribute to the perceived equity premium. First and most intuitively, the agent's risk aversion causes her to demand a substantial equity premium in the face of excess return volatility. Second, return extrapolation gives rise to perceived persistence of both the aggregate dividend process and, to a lesser extent, the aggregate consumption process. Under Epstein-Zin preferences, this perceived persistence is significantly priced, pushing up the equity premium. ${ }^{18}$ Here we note that prior work by Hirshleifer, Li, and Yu (2015) has pointed out a similar mechanism: in their model, extrapolative beliefs lead the agent to overestimate the persistence of productivity growth and hence the persistence of consumption growth. This perceived persistence of consumption growth, together with Epstein-Zin preferences, amplifies the equity premium.

With incorrect beliefs, the true equity premium can be different from the perceived one: on average, the true equity premium in our model is higher. Why is this the case? We observe that the perceived dividend growth is on average lower than the true dividend growth: $\mathbb{E}\left[g_{D}^{e}\right]=0.91 \%<$ $g_{D}=2.45 \%{ }^{19}$ As such, relative to the stock market price that the agent sets, the realized price growth - this is in part driven by the realized dividend growth - will, on average, be higher than she thinks it will be, causing the true equity premium to be higher than the perceived one.

The equity premium is not only high on average, but is also countercyclical and turns negative during high-sentiment periods: the equity premium averaged over the top quartile of the sentiment distribution is $-7.10 \%$. In general, rational expectations models do not generate a negative equity premium at any time. In our model, however, subjective expectations and objective expectations about stock market returns differ significantly during high- and low-sentiment periods: when sentiment is high, the agent expects high stock market returns moving forward, but precisely because of her incorrect beliefs, future stock market returns are low on average, generating a negative equity premium. This model implication is consistent with the recent empirical findings of Greenwood and Hanson (2013), Baron and Xiong (2017), and Cassella and Gulen (2018): these papers show that the expected excess return turns negative during high-sentiment periods.

Return predictability. Next, we examine the model's implications for the predictability of stock market returns. Empirically, Campbell and Shiller (1988) and Fama and French (1988) show that

\footnotetext{
${ }^{18}$ The agent is averse to persistent shocks when $\gamma>\psi$; for our choice of parameter values, this condition is satisfied.

${ }^{19}$ Empirically, we do not find that the survey expectation of dividend growth is on average lower than realized dividend growth.
} 
a regression of future log excess returns on the current log price-dividend ratio gives a negative and significant regression coefficient. Moreover, the predictive power of the price-dividend ratio is greater when future returns are calculated over longer horizons.

\section{[Place Table 5 about here]}

Table 5 reports the regression coefficient $\beta_{j}$ and the $R$-squared for a regression of the log excess return of the stock market from time $t$ to time $t+j$ on the current log price-dividend ratio

$$
r_{t \rightarrow t+j}^{D, e}=\alpha_{j}+\beta_{j} \ln \left(P_{t}^{D} / D_{t}\right)+\varepsilon_{j, t}
$$

where the time horizon $j=1,2,3,5$, and 7 (years). For each $j$, we calculate the regression coefficient $\beta_{j}$ and the $R$-squared using 10,000 years of monthly data simulated from the model, and compare them side by side with the empirical values. Consistent with the data, $\beta_{j}$ is negative and its magnitude increases as the time horizon $j$ increases. When the stock market has had high past price growth, the agent's expectation about future price growth increases, pushing up the current price-dividend ratio. Since the agent's expectation - the sentiment variable - tends to revert back to its mean, subsequent returns are low on average, giving rise to a negative regression coefficient in $(29)$.

The magnitudes of the regression coefficient and the $R$-squared generated from the model are broadly consistent with the empirical values. One difference, however, is that in the model, the $R$-squared begins to decrease as the time horizon $j$ increases beyond two years, whereas in the data, the $R$-squared keeps rising over longer horizons. To understand this difference, recall that we calibrate the model's belief parameters to survey expectations data by setting $\theta$ to 0.5 and setting $\chi$ to 0.2 : the agent looks back a couple of years when forming beliefs about future returns. Given this parameter choice, the mean reversion of sentiment tends to occur over the first few years. Over longer horizons, no additional mean reversion in the agent's beliefs contributes to the predictability of stock market returns. We return to this point in Section 4 and provide additional discussion.

Correlation between stock market returns and consumption growth. We now examine the model's implications for the correlation between stock market returns and consumption growth. Empirically, Hansen and Singleton $(1982,1983)$ show that this correlation is low. Nonetheless, many existing 
models have a consumption-based pricing kernel as the only source of stock market movements, resulting in a high, if not perfect, correlation between stock market returns and consumption growth. ${ }^{20}$

We compute the correlation between annual log consumption growth and annual excess stock market returns using 10,000 years of monthly data simulated from the model. The correlation is 0.19 ; in the data, it is $0.09 .^{21}$ In our model, we assume that the bias in the agent's beliefs about consumption growth comes only from the bias in her beliefs about dividend growth. Given the low correlation in the data between consumption growth and dividend growth, the bias in the agent's beliefs about consumption growth is small. As a result, the agent's beliefs about stock market returns, which comove strongly with her beliefs about dividend growth, are not significantly affected by fluctuations in consumption growth, giving rise to the low observed correlation between stock market returns and consumption growth.

We further examine how the correlation between log consumption growth and excess stock market returns changes at different horizons. In particular, we time-aggregate the monthly simulated data to the frequency of a quarter, a year, and five years. At each of these frequencies, the correlation between $\log$ consumption growth and excess returns is $0.2,0.19$, and 0.21 , respectively. That is, the correlation stays flat and close to the instantaneous correlation $\rho$ between $d D_{t}$ and $d C_{t}$. This result represents a potential limitation of the model because it is counter to $\mathrm{Yu}(2012)$, who shows empirically that the correlation between consumption growth and excess stock market returns increases significantly with the horizon.

Autocorrelations of asset prices. Finally, we check the model's implications for the autocorrelations of asset prices. Table 6 presents the empirical and theoretical values for the autocorrelations of $\log$ price-dividend ratios and log excess returns. Empirically, price-dividend ratios are highly persistent at short lags. Nonetheless, the model produces a persistence for the price-dividend ratio that is lower than the empirical value: the autocorrelation of $\ln \left(P^{D} / D\right)$ with a lag of three years is 0.5 in the data, but it is essentially zero in the model.

\footnotetext{
${ }^{20}$ One exception is Barberis, Huang, and Santos (2001). They use "narrow framing," the notion that investors can evaluate financial risks in isolation from consumption risks, to generate a low correlation between consumption growth and stock market returns. Specifically, they use power utility as the agent's preferences over consumption, but use prospect theory, developed by Kahneman and Tversky (1979), as the agent's preferences over financial wealth.

${ }^{21}$ This empirical value is from Campbell and Cochrane (1999).
} 


\section{[Place Table 6 about here]}

This low persistence of the price-dividend ratio poses a challenge to the model. In the model, the persistence of the price-dividend ratio is driven by the persistence of the agent's beliefs. The available survey evidence suggests that investors focus on just the past year or two when forming beliefs about future returns. As such, when calibrated to surveys by setting $\theta=0.5$ and $\chi=$ 0.2 , the agent's beliefs tend to mean-revert in a couple of years. However, to match the empirical persistence of the price-dividend ratio, the agent's beliefs need to be much more persistent: the agent needs to form beliefs about future returns based on many years of past returns. Section 4 discusses a potential resolution of this issue.

\subsection{Model implications for cash-flow expectations}

The model is calibrated to match survey evidence on return expectations. What are its implications for cash-flow expectations? Recall the expectations transmission mechanism described by Eq. (11): given that the price-dividend ratio is an increasing function of sentiment and that it is perceived to be mean-reverting, the agent's expectation about dividend growth is more responsive to changes in sentiment than her expectation about price growth. Moreover, we note that the total return equals the sum of the price growth and the dividend yield, with the latter being a decreasing

function of sentiment. As such, the agent's expectation about stock market returns is even less responsive to changes in sentiment, compared to her expectation about price growth.

\section{[Place Fig. 1 about here]}

Fig. 1 plots the agent's expectation about stock market returns, $\mathbb{E}^{e}\left[\left(d P_{t}^{D}+D_{t} d t\right) /\left(P_{t}^{D} d t\right)\right]$, the agent's expectation about price growth, $\mathbb{E}^{e}\left[d P_{t}^{D} /\left(P_{t}^{D} d t\right)\right]$, and the agent's expectation about dividend growth, $\mathbb{E}^{e}\left[d D_{t} /\left(D_{t} d t\right)\right]$, each as a function of the sentiment variable $S_{t}$. Fig. 1 shows that a one-standard-deviation $(2.12 \%)$ increase in sentiment from its mean $(1.30 \%)$ pushes up the agent's expectation about stock market returns from $6.49 \%$ to $7.09 \%$, a small increase of $0.61 \%$, while it pushes up the agent's expectation about dividend growth from $0.25 \%$ to $5.84 \%$, a much larger increase of $5.59 \% .^{22}$

\footnotetext{
${ }^{22}$ For the distribution of sentiment, the probability of the agent's price growth expectations approaching the boundaries of $\mu_{H}=12.5 \%$ and $\mu_{L}=-12.5 \%$ is approximately zero: specifically, the probability that $S$ falls below $-10 \%$ is $9.57 \times 10^{-8}$, and the probability that $S$ goes above $10 \%$ is $3.34 \times 10^{-8}$.
} 
To directly test the relation specified in Eqs. (8) to (11) between the agent's expectation- either about future dividend growth or about future returns - and her sentiment, we examine survey expectations data. Specifically, for measures of return expectations, we use data from Cassella and Gulen (2018), namely, time-series data of investors' return expectations from the Gallup survey, the American Association of Individual Investors survey, and the Investors' Intelligence newsletter expectations survey. For the measure of dividend growth expectations, we use data from De la $\mathrm{O}$ and Myers (2021), namely, time-series data of investors' dividend growth expectations, aggregated from analyst forecasts of dividends of individual firms in the S\&P 500; these dividend forecasts are from the Thomson Reuters Institutional Brokers Estimate System (I/B/E/S). Finally, for measures of sentiment, we examine two proxies at each point in time: the stock market's past 12-month cumulative return $R_{t-12 \rightarrow t}^{D}$; and the model-implied sentiment $S_{t}$, constructed from Eq. (7). ${ }^{23}$

\section{[Place Table 7 about here]}

Table 7 reports the regression coefficient and the $t$-statistic (in parentheses), the intercept, the number of observations, and the $R$-squared, estimated from a regression of investor expectationseither about future dividend growth or about future returns - on investor sentiment. Table 7 confirms Eqs. (8) to (11): that investors' dividend growth expectations depend positively on sentiment; that investors' return expectations depend positively on sentiment; and that the magnitude of the regression coefficient on sentiment is larger when the dependent variable is investors' dividend growth expectations, compared to when the dependent variable is investors' return expectations. One limitation is that, when regressing investors' dividend growth expectations on $S_{t}$, the $t$-statistic for the regression coefficient is small, indicating that the coefficient does not differ from zero in a statistically significant way. This result is likely due to the fact that we only have 51 quarters of annual forecasts of dividend growth from De la O and Myers (2021); as the sample size grows bigger over time, we expect to observe a more significant relation between dividend growth expectations and sentiment. Overall, the results presented in Table 7 provide direct support for Eqs. (8) to (11),

\footnotetext{
${ }^{23}$ For the model-implied sentiment $S_{t}$, we set its initial value to $g_{D}$; we feed the model with a time series of monthly price growth of the stock market (obtained from CRSP), starting from January 1926; and we compute a discretized version of $d \omega_{t}^{e}$ in Eq. (7) for each month, based on which we derive monthly sentiment from January 1926 to September 2015. Note that $g_{D}$ is the correct value for $S_{t}$ if the agent is fully rational $(\theta=1)$. Our findings do not depend strongly on the initial value of sentiment because we construct this time series of sentiment starting at a very early date, January 1926.
} 
which highlight the key mechanism of the model.

To further understand how the agent's cash-flow and return expectations affect stock market movements, we follow the procedure in Campbell and Shiller (1988) to decompose, in the context of the model, the log price-dividend ratio of the stock market:

$$
\ln \left(P_{t}^{D} / D_{t}\right) \approx \sum_{j=0}^{\infty} \xi^{j}\left(\Delta d_{(t+j \Delta t) \rightarrow(t+(j+1) \Delta t)}-r_{(t+j \Delta t) \rightarrow(t+(j+1) \Delta t)}^{D}\right)-(\ell \operatorname{n}(\xi)+(1-\xi) \zeta) /(1-\xi)
$$

where $\zeta$ is the in-sample average of the annual $\log$ dividend-price ratio; $\xi=e^{-\zeta} /\left(\Delta t+e^{-\zeta}\right)$; $\Delta d_{(t+j \Delta t) \rightarrow(t+(j+1) \Delta t)}$ is the log dividend growth from time $t+j \Delta t$ to $t+(j+1) \Delta t$; and $r_{(t+j \Delta t) \rightarrow(t+(j+1) \Delta t)}^{D}$ is the log stock market return over the same period. Eq. (30) says that the movement of the price-dividend ratio comes from either the movement of future dividend growth - the "cash-flow news" - or the movement of future returns - the "discount rate news." The standard approach that empirically addresses the relative importance of these two components is to look at future realized dividend growth and returns, and compute

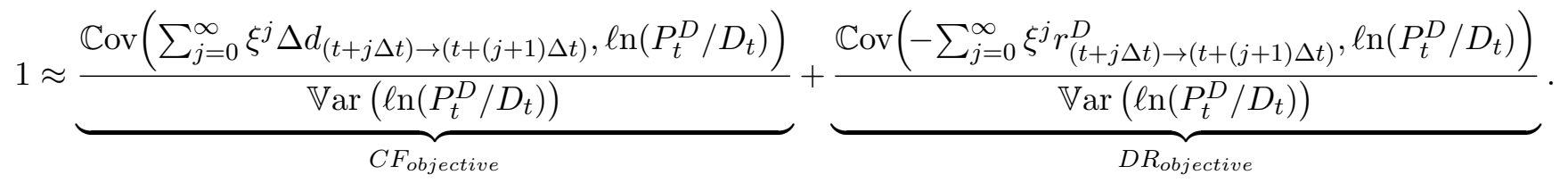

The first term on the right hand side of $(31), C F_{\text {objective }}$, is the contribution of changes in cash-flow news to stock market movements, and the second term, $D R_{\text {objective }}$, is the contribution of changes in discount rate news to stock market movements. Most empirical studies that have conducted a Campbell-Shiller decomposition take this approach.

With incorrect beliefs, the model allows us to further study the relation between the agent's subjective expectations and stock market movements by taking the subjective expectations on both sides of (30) and computing

$$
1 \approx \underbrace{\frac{\operatorname{Cov}\left(\mathbb{E}_{t}^{e}\left[\sum_{j=0}^{\infty} \xi^{j} \Delta d_{(t+j \Delta t) \rightarrow(t+(j+1) \Delta t}\right], \ell \ln \left(P_{t}^{D} / D_{t}\right)\right)}{\operatorname{Var}\left(\ln \left(P_{t}^{D} / D_{t}\right)\right)}}_{C F_{\text {subjective }}}+\underbrace{\frac{\operatorname{Cov}\left(-\mathbb{E}_{t}^{e}\left[\sum_{j=0}^{\infty} \xi^{j} r_{(t+j \Delta t) \rightarrow(t+(j+1) \Delta t)}^{D}\right], \ell \ln \left(P_{t}^{D} / D_{t}\right)\right)}{\mathbb{V a r}\left(\ln \left(P_{t}^{D} / D_{t}\right)\right)}}_{D R_{\text {subjective }}} .
$$


The first term on the right hand side of $(32), C F_{\text {subjective }}$, is the contribution of changes in subjective expectations about cash-flow news to stock market movements, and the second term, $D R_{\text {subjective }}$, is the contribution of changes in subjective expectations about discount rate news to stock market movements.

\section{[Place Table 8 about here]}

Table 8 reports the four coefficients, $C F_{\text {objective }}, D R_{\text {objective }}, C F_{\text {subjective }}, D R_{\text {subjective }}$, as well as their corresponding $R$-squared. These coefficients and $R$-squared are calculated using 10,000 years of monthly data simulated from the model. By using future realized dividend growth and stock market returns, we obtain $D R_{\text {objective }}=0.96$ with an $R$-squared of 0.06 and $C F_{\text {objective }}=0.04$ with an $R$-squared of $1.1 \times 10^{-4}$. This result replicates the empirical finding of the volatility test literature that the variation of the price-dividend ratio comes primarily from discount rate variation (see Cochrane, 2011).

On the other hand, by using the agent's subjective expectations about dividend growth and returns, we obtain $D R_{\text {subjective }}=-0.10$ with an $R$-squared of 0.98 and $C F_{\text {subjective }}=1.10$ with an $R$-squared of 0.98. When sentiment becomes higher, the increase in the agent's cash-flow expectations is much larger than the increase in her return expectations. The former tends to push up the price-dividend ratio, while the latter tends to push down the price-dividend ratio, but to a lesser extent. As such, $C F_{\text {subjective }}$ is a positive number that is greater than one, whereas $D R_{\text {subjective }}$ is a small negative number. This result unveils a very different picture that highlights the importance of expectations data: changes in the agent's subjective expectations about future cash-flow news explain the majority of stock market movements. In one of their empirical specifications, De la $\mathrm{O}$ and Myers $(2021)$ find that $D R_{\text {subjective }}=-0.09$ and $C F_{\text {subjective }}=1.09 .{ }^{24}$ These values match the theoretical results from our model.

Importantly, the fact that prices in our model are mainly correlated with cash-flow expectations is a consequence of the Campbell-Shiller accounting identity; this statement is about correlation, not about causality. In the model, the agent's return expectations determine her cash-flow expectations and are the cause of price movements. Together, Tables 1 and 8 show that our model simultaneously accounts for the empirical findings of Greenwood and Shleifer (2014) on return expectations and

\footnotetext{
${ }^{24}$ See Table VI of their paper.
} 
the empirical findings of De la O and Myers (2021) on cash-flow expectations. ${ }^{25}$

We conclude Section 3 by discussing the role of rational arbitrageurs. The model has a representative agent whose beliefs are biased. One natural question is: if we introduce rational arbitrageurs, to what extent can they counteract the mispricing caused by the behavioral agent and therefore attenuate the significance of the model implications? Developing such a two-agent model is beyond the scope of the paper. Nonetheless, three observations suggest that our model implications are likely to remain intact after taking rational arbitrageurs into account.

First, as pointed out by Barberis, Greenwood, Jin, and Shleifer (2015), extrapolative expectations are persistent in a dynamic model, which means that the behavioral agents who extrapolate past returns have persistently high demand for the stock market following high stock market returns. The persistence of this demand prevents near-future stock market returns from becoming too low, reducing the incentive of rational agents to counteract mispricing. In other words, the persistence of extrapolative beliefs limits the impact of rational arbitrageurs on asset prices. Second, in an economy with heterogeneous beliefs, asset prices are jointly determined by agents' beliefs, weighted by their risk tolerances. A positive fundamental shock causes optimists to gain a larger fraction of wealth and increases their risk tolerance relative to pessimists, which in turn gives optimists a greater weight in pushing up asset prices. As a result, heterogeneity in investor beliefs can be an additional source of excess volatility; it can further amplify, rather than attenuate, our model implications. ${ }^{26}$ Finally, in an economy with both rational and behavioral agents who have recursive preferences, the behavioral agents could eventually dominate the market: there is a positive probability that they take up most of the wealth in the economy in the long run. This is a key finding in Borovicka (2020). It suggests that our model's implications can be the limiting implications of a model with both rational and behavioral agents in the initial period.

\footnotetext{
${ }^{25}$ In Appendix D, we provide additional discussion about the relation between return expectations and cash-flow expectations.

${ }^{26}$ See Xiong (2013) for more discussion of this amplification mechanism.
} 


\section{Discussion}

\subsection{An alternative calibration}

As we show in Section 3, calibrating the agent's belief parameters to match return expectations data analyzed in Greenwood and Shleifer (2014) allows the model to quantitatively explain a set of important facts about stock market prices, return expectations, and cash-flow expectations. However, we also find that the model generates less predictability of stock market returns beyond two years, compared to the data. Moreover, the model produces a persistence for the price-dividend ratio that is lower than the empirical value.

One possible resolution would posit that the survey expectations are a noisy reflection of investors' actual beliefs that drive asset prices: these beliefs could put more weight on distant past returns than is revealed by survey expectations data. ${ }^{27}$ This line of reasoning motivates the following analytical exercise. We set $\chi$ to 0.02 while keeping all other parameter values unchanged, so that the agent in our model puts substantial weight even on distant past returns - sufficient weight, in fact, that the model matches the empirical persistence of the price-dividend ratio. We then examine whether the model can still explain other facts about asset prices - and find that it does.

\section{[Place Tables 9 and 10 about here]}

Table 9 shows the precise comparison between the model-implied autocorrelations of log pricedividend ratios and their empirical counterparts, with $\chi$ now set to 0.02. By construction, the theoretical values match up closely with the empirical values. For the autocorrelations of log excess returns, the model-implied values are also broadly consistent with the empirical ones. Table 10 reports the regression coefficient $\beta_{j}$ and the $R$-squared for the regression of the log excess return of the stock market from time $t$ to time $t+j$ on the current log price-dividend ratio, as described previously in Eq. (29). By setting $\chi$ to 0.02 , the model produces a predictability of stock market returns that matches the data very well: the magnitudes of the regression coefficient $\beta_{j}$ and the

\footnotetext{
${ }^{27}$ Malmendier and Nagel (2011) regress household stock holdings on a weighted average of past stock market returns. They find that household stock holdings put weights on past stock market returns that are positive and that decline, the further back these returns go into the past. Moreover, they show that stock holdings depend even on distant past returns.
} 
$R$-squared generated by the model both increase as the time horizon $j$ increases, consistent with the data.

Overall, we find that adjusting the value of $\chi$ mainly affects the model's implication for the persistence of asset prices. The model's implications for many other quantities remain stable. First, the model continues to generate a high equity premium (9.81\%), significant return volatility (27.1\%), a low risk-free rate $(2.12 \%)$, low volatility of the risk-free rate $(0.19 \%)$, and a low correlation between stock market returns and consumption growth (0.20). Second, the model continues to match the empirical finding of De la O and Myers (2021) on cash-flow expectations, namely that changes in the agent's subjective expectations about future cash-flow news explain the majority of stock market movements. Finally, the model is able to explain some additional facts about asset prices and cash-flow expectations documented in Nagel and Xu (2021). Specifically, these authors find that a weighted average of past returns or cash flows going back a long way — what they call "experienced returns" or "experienced payout growth" - predicts subsequent returns with a negative sign. They also find that subjective cash-flow expectations are positively related to a weighted average of past returns or cash flows. With $\chi$ set to 0.02 , our model matches both facts.

To summarize, we observe a "frequency disconnect" between investor beliefs and asset prices: survey expectations data suggest that real-world investors' beliefs about stock market returns depend mainly on recent past returns; however, to match the empirical persistence of the pricedividend ratio, investors need to form beliefs about future stocks based on many years of past returns. In the model, calibrating the agent's beliefs to directly match the empirical persistence of the price-dividend ratio provides one potential resolution of this issue, but there can be other possible resolutions. We leave a full reconciliation of the survey expectations about stock market returns and the observed persistence of asset prices to future research.

\subsection{Comparative statics}

In this section, we examine the sensitivity of the model's implications to changes in some of the parameter values. Specifically, we study how changes in $\gamma$, the coefficient of relative risk aversion, and $\psi$, the reciprocal of the elasticity of intertemporal substitution, affect the equity premium and the volatility of stock market returns. 


\section{[Place Fig. 2 about here]}

Fig. 2 plots the average equity premium, measured by either the average log excess return or the average excess return, and the average volatility of stock market returns, each as a function of $\gamma$ or $\psi$. The coefficient of relative risk aversion is positively related to the equity premium but negatively related to the volatility of returns. Lower risk aversion leads the agent to require a lower equity premium for risk compensation; reducing $\gamma$ from ten to five, the model still explains $66.5 \%$ of the observed equity premium. At the same time, lower risk aversion strengthens the elasticity of the agent's demand for the stock market as sentiment changes. This in turn leads to higher return volatility.

The average equity premium and the average return volatility remain high as we change the elasticity of intertemporal substitution from 0.5 to 2 ; for example, setting the elasticity of intertemporal substitution to 0.5 , our model generates an equity premium of $5.92 \%$. Overall, our model's implications are quantitatively robust to significant changes in $\psi$.

\subsection{Comparison with alternative models}

In this section, we compare our model with several alternative models of the aggregate stock market. $^{28}$ First, we provide a quantitative comparison between our model and a model with fundamental extrapolation, in which the agent holds extrapolative expectations about the dividend growth of the stock market. Next, we discuss some differences between our model and rational expectations models.

A fundamental extrapolation model. A literature in behavioral finance focuses on fundamental extrapolation, the notion that some investors hold extrapolative expectations about asset fundamentals such as dividend growth or GDP growth (Barberis, Shleifer, and Vishny, 1998; Fuster, Hebert, and Laibson, 2011; Choi and Mertens, 2013; Alti and Tetlock, 2014; Hirshleifer, Li, and Yu, 2015; Bordalo, Gennaioli, LaPorta, and Shleifer, 2020). In this section, we provide a quantitative comparison between our model and a model with fundamental extrapolation. To facilitate this comparison, we keep the two models almost identical. The only difference is that, in the model with fundamental extrapolation, sentiment is constructed from past dividend growth, whereas in

\footnotetext{
${ }^{28}$ For this comparison, we return to the benchmark values for the model parameters; we set $\chi$ to 0.2 .
} 
the model with return extrapolation, sentiment is constructed from past price growth. We provide more discussion of this fundamental extrapolation model in Appendix E.

The model with fundamental extrapolation and the model with return extrapolation can be compared in many aspects. Here, we focus on the two models' implications for investor expectations. Panel A of Table 11 reports the regression coefficient, its $t$-statistic, the intercept, and the $R$ squared for a regression of the agent's time- $t$ expectation about the future stock market return on the past 12-month cumulative return, using the fundamental extrapolation model described in Appendix E. The $t$-statistics of the regression coefficient are insignificant, meaning that the agent's return expectations do not depend significantly on past 12-month returns; as a comparison, Table 1 shows that, in the model with return extrapolation, the agent's return expectations are a strong positive function of past 12-month returns. Panel B of Table 11 reports the regression coefficient, its $t$-statistic, the intercept, and the $R$-squared for a regression of the agent's time- $t$ expectation about future dividend growth on the past 12-month dividend growth, using the return extrapolation model described in Section 2. The t-statistics of the regression coefficient are highly significant, meaning that the agent's dividend growth expectations depend strongly on past dividend growth.

\section{[Place Table 11 about here]}

To understand these results, suppose past dividend growth has been high. This results in high past returns. Fundamental extrapolation leads the agent to expect high dividend growth moving forward, but not high returns: following high past dividend growth, the stock market price increases to the extent that the agent's expectation of future returns does not change significantly. Recall from Greenwood and Shleifer (2014) that, empirically, past 12-month returns do positively predict survey expectations about future returns. As such, a fundamental extrapolation model with a representative agent faces a challenge in explaining survey expectations about stock market returns. ${ }^{29}$ On the other hand, when past dividend growth has been high - and hence past returns have been high - Eq. (10) suggests that return extrapolation leads the agent to expect high dividend growth moving forward. ${ }^{30}$ As a result, while our model assumes only return extrapolation, it also

\footnotetext{
${ }^{29} \mathrm{~A}$ fundamental extrapolation model with heterogeneous agents - for instance, one with an agent who extrapolates from past dividend growth and an agent who is fully rational - can generate extrapolative expectations of returns for the behavioral agent in the model. See the model of Ehling, Graniero, and Heyerdahl-Larsen (2018) as an example.

${ }^{30}$ We have provided empirical support for Eq. (10) in Table 7.
} 
produces patterns of investor beliefs that are consistent with fundamental extrapolation.

The comparison between the model with fundamental extrapolation and the model with return extrapolation also highlights a methodological contribution of our paper. In most asset pricing models, the state variables for agents' beliefs can be exogenously specified without solving the equilibrium; this greatly simplifies these models. Take the fundamental extrapolation model described above as an example. Eq. (E.1) in Appendix E characterizes the evolution of sentiment $S$, the state variable that drives the dynamics of asset prices. This equation can be derived without solving the equilibrium. However, with return extrapolation, sentiment $S$ determines - and is endogenously determined by - asset prices. As a result, such a model requires solving for beliefs and asset prices simultaneously; this represents a greater modeling challenge. Our numerical approach to solving a system of differential equations provides a solution to this challenge.

A true regime-switching model. We now compare our model with models with rational expectations. Specifically, we look at a true regime-switching model. Recall first that, in our return extrapolation model, the agent believes that the expected growth rate of stock market prices follows a regime-switching process; see Eqs. (6) and (7) from Section 2. Moreover, the agent's beliefs are incorrect: the agent does not form rational expectations to learn over time that the perceived regime-switching process for price growth differs from the true process.

What if we instead assume that the regime-switching process is the true data-generating process? In this case, the agent's beliefs about price growth become fully rational. The true evolution of the stock market price is

$$
d P_{t}^{D} / P_{t}^{D}=\left[(1-\theta) g_{D}+\theta \tilde{\mu}_{S, t}\right] d t+\sigma_{P}^{D}\left(S_{t}\right) d \omega_{t}^{P},
$$

where $\omega_{t}^{P}$ is a standard Brownian motion, and the latent variable $\tilde{\mu}_{S, t}$ follows the regime-switching process specified in (6). As with the behavioral model, the agent in this rational expectations model does not directly observe $\tilde{\mu}_{S, t}$. Instead, she uses past stock market prices to form a Bayesian estimate of $\tilde{\mu}_{S, t}: S_{t}=\mathbb{E}\left[\tilde{\mu}_{S, t} \mid \mathcal{F}_{t}^{P}\right]$. We further assume that the perceived dividend process (10) and the perceived consumption process (14) are also rational.

By construction, this rational expectations model produces the same equilibrium prices as our behavioral model: the solutions to the differential equations in (A.5) and (A.9) also apply to this 
model. Nonetheless, the two models have statistical properties that are significantly different. One difference, for instance, lies in the models' implications for the predictability of stock market returns.

\section{[Place Table 12 about here]}

Table 12 reports the regression coefficient $\beta_{j}$ and the $R$-squared for a regression of the $\log$ excess return of the stock market from time $t$ to time $t+j$ on the current log price-dividend ratio $\ln \left(P_{t}^{D} / D_{t}\right)$ over various time horizons $j$ (one to seven years), now using the true regime-switching model. Table 12 shows that the model fails to produce the predictability of stock market returns documented in Campbell and Shiller (1988) and Fama and French (1988): both the regression coefficients and the $R$-squared are close to zero. In contrast, Table 5 shows that the behavioral model with return extrapolation produces the observed predictability of stock market returns.

With rational expectations, the agent's beliefs about stock market returns are on average correct. Therefore, following high past price growth, the agent properly anticipates high future price growth, which pushes down the dividend yield in equilibrium, giving rise to flat returns in subsequent periods. As a result, future returns do not vary significantly with the current price-dividend ratio, leading to little return predictability in the true regime-switching model.

\section{Conclusion}

We build a new model of return extrapolation that simultaneously accounts for some important facts about asset prices, return expectations, and cash-flow expectations. With the agent's beliefs calibrated to fit survey expectations about stock market returns, the model quantitatively matches the long-run properties of stock market prices: it generates a high average equity premium, significant excess volatility, a low average interest rate, low interest rate volatility, and a price-dividend ratio whose average level matches the empirical one. The model also explains some dynamic aspects of stock market prices: it produces significant predictability of stock market returns and the observed low correlation between stock market returns and consumption growth. Moreover, the model predicts that changes in cash-flow expectations explain the majority of stock market

movements, which is consistent with recent empirical findings. Finally, we provide a quantitative 
comparison between our model and alternative models of the stock market, and demonstrate their distinct implications for asset prices and for investor expectations.

Our analysis leaves open several areas for future research. First, it remains a challenge to reconcile survey expectations about stock market returns and the empirical persistence of the price-dividend ratio. Second, our representative-agent model neglects an important channel that affects asset prices: the time-varying fraction of wealth held by behavioral agents. Explicitly incorporating rational agents into our framework could lead to additional implications. Finally, the extrapolation framework is closely linked to theories of model uncertainty. A careful investigation of this connection could produce useful insights for both literatures. 


\section{Appendix A. Derivation of the model solution}

In this section, we derive the differential equations that determine the price-dividend ratio $f\left(S_{t}\right)$

and the wealth-consumption ratio $l\left(S_{t}\right)$. First, for the subjective Euler equation (4), setting $\tilde{R}_{j, t+d t}$, the return on a tradeable asset, to the gross return on the stock market, the equation becomes

$$
\mathbb{E}_{t}^{e}\left[e^{-\delta(1-\gamma) d t /(1-\psi)}\left(\frac{\tilde{C}_{t+d t}}{C_{t}}\right)^{-\psi(1-\gamma) /(1-\psi)}\left(\frac{\tilde{P}_{t+d t}^{C}+\tilde{C}_{t} d t}{P_{t}^{C}}\right)^{(\psi-\gamma) /(1-\psi)} \frac{\tilde{P}_{t+d t}^{D}+\tilde{D}_{t+d t} d t}{P_{t}^{D}}\right]=1
$$

Using Taylor expansion, (A.1) becomes

$$
\begin{aligned}
& \mathbb{E}_{t}^{e}\left[e^{-\delta(1-\gamma) d t /(1-\psi)}\left(\tilde{C}_{t+d t}\right)^{-\psi(1-\gamma) /(1-\psi)}\left(\tilde{P}_{t+d t}^{C}\right)^{(\psi-\gamma) /(1-\psi)} \tilde{P}_{t+d t}^{D}\left(1+\frac{\psi-\gamma}{1-\psi} \frac{\tilde{C}_{t+d t}}{\tilde{P}_{t+d t}^{C}} d t+\frac{\tilde{D}_{t+d t}}{\tilde{P}_{t+d t}^{D}} d t\right)\right] \\
& =C_{t}^{-\psi(1-\gamma) /(1-\psi)}\left(P_{t}^{C}\right)^{(\psi-\gamma) /(1-\psi)} P_{t}^{D} .
\end{aligned}
$$

Rearranging terms gives

$$
0=\mathbb{E}_{t}^{e}\left[\begin{array}{l}
d\left(\Theta C^{(\psi-\gamma) /(1-\psi)} l^{(\psi-\gamma) /(1-\psi)} D f\right)+\frac{\psi-\gamma}{1-\psi} \Theta C^{(\psi-\gamma) /(1-\psi)} l^{(2 \psi-\gamma-1) /(1-\psi)} D f d t \\
+\Theta C^{(\psi-\gamma) /(1-\psi)} l^{(\psi-\gamma) /(1-\psi)} D d t
\end{array}\right],
$$

where $\Theta(C, t) \equiv e^{-\delta(1-\gamma) t /(1-\psi)} C^{-\psi(1-\gamma) /(1-\psi)}$. Applying Ito's lemma to (A.3) leads to

$$
0=\mathbb{E}_{t}^{e}\left[\begin{array}{l}
-\frac{\delta(1-\gamma)}{1-\psi} d t-\gamma(d C / C)+(d D / D)+(d f / f)+\frac{\psi-\gamma}{1-\psi}(d l / l)+\frac{\gamma(\gamma+1)}{2}(d C / C)^{2} \\
+\frac{1}{2} \frac{\psi-\gamma}{1-\psi} \frac{2 \psi-\gamma-1}{1-\psi}(d l / l)^{2}-\frac{\gamma(\psi-\gamma)}{1-\psi}(d C / C)(d l / l)-\gamma(d C / C)(d D / D)-\gamma(d C / C)(d f / f) \\
+\frac{\psi-\gamma}{1-\psi}(d l / l)(d D / D)+\frac{\psi-\gamma}{1-\psi}(d l / l)(d f / f)+(d f / f)(d D / D)+\frac{\psi-\gamma}{1-\psi} l^{-1} d t+f^{-1} d t
\end{array}\right]
$$


Using (7), (10), and (14) to further simplify (A.4) gives

$$
0=\left[\begin{array}{l}
-\frac{(1-\gamma)}{1-\psi} \delta-\gamma g_{C}^{e}+g_{D}^{e}+\left[\left(f^{\prime} / f\right)+\frac{\psi-\gamma}{1-\psi}\left(l^{\prime} / l\right)\right] \mu_{S}^{e}+\frac{1}{2}\left[\left(f^{\prime \prime} / f\right)+\frac{\psi-\gamma}{1-\psi}\left(l^{\prime \prime} / l\right)\right] \sigma_{S}^{2} \\
+\frac{\gamma(\gamma+1)}{2} \sigma_{C}^{2}+\frac{1}{2} \frac{\psi-\gamma}{1-\psi} \frac{2 \psi-\gamma-1}{1-\psi}\left(l^{\prime} / l\right)^{2} \sigma_{S}^{2}-\frac{\gamma(\psi-\gamma)}{1-\psi} \rho \sigma_{C} \sigma_{S}\left(l^{\prime} / l\right)-\gamma \rho \sigma_{C} \sigma_{D}-\gamma \rho \sigma_{C} \sigma_{S}\left(f^{\prime} / f\right) \\
+\frac{\psi-\gamma}{1-\psi} \sigma_{D} \sigma_{S}\left(l^{\prime} / l\right)+\frac{\psi-\gamma}{1-\psi} \sigma_{S}^{2}\left(l^{\prime} / l\right)\left(f^{\prime} / f\right)+\sigma_{D} \sigma_{S}\left(f^{\prime} / f\right)+\frac{\psi-\gamma}{1-\psi} l^{-1}+f^{-1}
\end{array}\right] .
$$

Similarly, setting $\tilde{R}_{j, t+d t}$ in (4) to the gross return on the Lucas tree, the subjective Euler equation (4) becomes

$$
\mathbb{E}_{t}^{e}\left[e^{-\delta(1-\gamma) d t /(1-\psi)}\left(\frac{\tilde{C}_{t+d t}}{C_{t}}\right)^{-\psi(1-\gamma) /(1-\psi)}\left(\frac{\tilde{P}_{t+d t}^{C}+\tilde{C}_{t} d t}{P_{t}^{C}}\right)^{(1-\gamma) /(1-\psi)}\right]=1
$$

Rearranging terms yields

$$
0=\mathbb{E}_{t}^{e}\left[d\left(\Theta C^{(1-\gamma) /(1-\psi)} l^{(1-\gamma) /(1-\psi)}\right)+\frac{1-\gamma}{1-\psi} \Theta C^{(1-\gamma) /(1-\psi)} l^{(\psi-\gamma) /(1-\psi)} d t\right]
$$

Applying Ito's lemma to (A.7) leads to

$$
0=\mathbb{E}_{t}^{e}\left[\begin{array}{c}
-\frac{1-\gamma}{1-\psi} \delta d t-(\gamma-1)(d C / C)+\frac{\gamma(\gamma-1)}{2}(d C / C)^{2}+\frac{1-\gamma}{1-\psi}(d l / l) \\
+\frac{1}{2} \frac{1-\gamma}{1-\psi} \frac{\psi-\gamma}{1-\psi}(d l / l)^{2}+\frac{(1-\gamma)^{2}}{1-\psi}(d C / C)(d l / l)+\frac{1-\gamma}{1-\psi} l^{-1} d t
\end{array}\right]
$$

Using (7) and (14) to further simplify (A.8) gives

$$
0=\left[\begin{array}{l}
-\frac{1-\gamma}{1-\psi} \delta-(\gamma-1) g_{C}^{e}+\frac{\gamma(\gamma-1)}{2} \sigma_{C}^{2}+\frac{1-\gamma}{1-\psi}\left(l^{\prime} / l\right) \mu_{S}^{e}+\frac{1-\gamma}{2(1-\psi)}\left(l^{\prime \prime} / l\right) \sigma_{S}^{2} \\
+\frac{1}{2} \frac{1-\gamma}{1-\psi} \frac{\psi-\gamma}{1-\psi}\left(l^{\prime} / l\right)^{2} \sigma_{S}^{2}+\frac{(1-\gamma)^{2}}{1-\psi} \rho \sigma_{C} \sigma_{S}\left(l^{\prime} / l\right)+\frac{1-\gamma}{1-\psi} l^{-1}
\end{array}\right]
$$

Substituting $\mu_{S}$ and $\sigma_{S}$ from (7), $g_{D}^{e}$ and $\sigma_{P}^{D}$ from (11) and (12), and $g_{C}^{e}$ from (15) into Eqs. (A.5) and (A.9), we then arrive at two ordinary differential equations that jointly determine $f$ and $l .^{31}$

\footnotetext{
${ }^{31}$ When $\theta=0$, our model reduces to a fully rational benchmark. In this case, Eqs. (A.5) and (A.9) lead to$$
f=\left[\delta+\psi g_{C}-g_{D}-\frac{\gamma(\psi+1)}{2} \sigma_{C}^{2}+\gamma \rho \sigma_{C} \sigma_{D}\right]^{-1} \text { and } l=\left[\delta+(\psi-1) g_{C}-\frac{\gamma(\psi-1)}{2} \sigma_{C}^{2}\right]^{-1} .
$$ 
Regarding the boundary conditions for solving these two differential equations, note that, in (A.5) and (A.9), the second derivative terms are all multiplied by $\sigma_{S}$, and that $\sigma_{S}$ goes to zero as $S$ approaches either $\mu_{H}$ or $\mu_{L}$. As a result, $\mu_{H}$ and $\mu_{L}$ are both singular points, and therefore no boundary condition is required. 


\section{Appendix B. Steady-state distribution for sentiment}

In this section, we derive the steady-state distribution for $S_{t}$ as objectively measured by an outside econometrician. To that end, we first obtain the objective evolution of sentiment by substituting the change-of-measure equation (21) into the subjective evolution of sentiment in (7)

$$
d S_{t}=\left[\mu_{S}^{e}\left(S_{t}\right)+\sigma_{D}^{-1} \sigma_{S}\left(S_{t}\right)\left(g_{D}-g_{D}^{e}\left(S_{t}\right)\right)\right] d t+\sigma_{S}\left(S_{t}\right) d \omega_{t}^{D}
$$

Compared to the subjective evolution of sentiment, the objective evolution exhibits a larger degree

of mean reversion: the additional term $\sigma_{D}^{-1} \sigma_{S}\left(S_{t}\right)\left(g_{D}-g_{D}^{e}\left(S_{t}\right)\right)$ in (B.1) is a negative function of sentiment.

Denote the objective steady-state distribution for sentiment as $\varphi(S)$. Based on (B.1), we then derive $\varphi(S)$ as the solution to the Kolmogorov forward equation

$$
\begin{aligned}
0= & \frac{1}{2} \frac{d^{2}}{d S^{2}}\left(\sigma_{S}^{2}(S) \varphi(S)\right)-\frac{d}{d S}\left(\left[\mu_{S}^{e}\left(S_{t}\right)+\sigma_{D}^{-1} \sigma_{S}\left(S_{t}\right)\left(g_{D}-g_{D}^{e}\left(S_{t}\right)\right)\right] \varphi(S)\right) \\
= & \left(\sigma_{S}^{\prime}\right)^{2} \varphi+\sigma_{S} \sigma_{S}^{\prime \prime} \varphi+2 \sigma_{S} \sigma_{S}^{\prime} \varphi^{\prime}+\frac{1}{2} \sigma_{S}^{2} \varphi^{\prime \prime} \\
& -\left[\left(\mu_{S}^{e}\right)^{\prime}+\sigma_{D}^{-1} \sigma_{S}^{\prime}\left(g_{D}-g_{D}^{e}\right)-\sigma_{D}^{-1} \sigma_{S}\left(g_{D}^{e}\right)^{\prime}\right] \varphi-\left[\mu_{S}^{e}+\sigma_{D}^{-1} \sigma_{S}\left(g_{D}-g_{D}^{e}\right)\right] \varphi^{\prime}
\end{aligned}
$$

where $\sigma_{S}$ and $g_{D}^{e}$ are from (7) and (11), respectively, and the expressions for $\sigma_{S}^{\prime}, \sigma_{S}^{\prime \prime},\left(\mu_{S}^{e}\right)^{\prime}$, and $\left(g_{D}^{e}\right)^{\prime}$ are derived as follows. From the expression of $\sigma_{S}$ in (7)

$$
\begin{aligned}
& \sigma_{S}^{\prime}=\frac{\theta \sigma_{P}^{D}\left(\mu_{H}+\mu_{L}-2 S\right)-\theta\left(\mu_{H}-S\right)\left(S-\mu_{L}\right)\left(\sigma_{P}^{D}\right)^{\prime}}{\left(\sigma_{P}^{D}\right)^{2}}, \\
& \sigma_{S}^{\prime \prime}=\frac{\theta\left(\mu_{H}-S\right)\left(S-\mu_{L}\right)\left\{2\left[\left(\sigma_{P}^{D}\right)^{\prime}\right]^{2}-\sigma_{P}^{D}\left(\sigma_{P}^{D}\right)^{\prime \prime}\right\}}{\left(\sigma_{P}^{D}\right)^{3}}-2 \theta \frac{\sigma_{P}^{D}\left(\sigma_{P}^{D}\right)^{\prime}\left(\mu_{H}+\mu_{L}-2 S\right)+\left(\sigma_{P}^{D}\right)^{2}}{\left(\sigma_{P}^{D}\right)^{3}} .
\end{aligned}
$$

From the expression of $\mu_{S}^{e}$ in (7) and the expression of $g_{D}^{e}$ in (11)

$$
\begin{aligned}
\left(\mu_{S}^{e}\right)^{\prime}= & -2 \chi \\
\left(g_{D}^{e}\right)^{\prime}= & \theta-\sigma_{D}\left(\sigma_{P}^{D}\right)^{\prime}-\mu_{S}^{\prime}\left(f^{\prime} / f\right)-\mu_{S}\left[f^{\prime \prime} / f-\left(f^{\prime}\right)^{2} / f^{2}\right] \\
& \quad-\sigma_{S} \sigma_{S}^{\prime}\left(f^{\prime \prime} / f\right)-\frac{1}{2} \sigma_{S}^{2}\left[f^{\prime \prime \prime} / f-f^{\prime} f^{\prime \prime} / f^{2}\right],
\end{aligned}
$$


where $\sigma_{P}^{D}$ is from $(11)$, and $\left(\sigma_{P}^{D}\right)^{\prime}$ and $\left(\sigma_{P}^{D}\right)^{\prime \prime}$ are

$$
\begin{aligned}
\left(\sigma_{P}^{D}\right)^{\prime}= & \frac{\theta\left(\mu_{H}+\mu_{L}-2 S\right)\left(f^{\prime} / f\right)+\theta\left(\mu_{H}-S\right)\left(S-\mu_{L}\right)\left[f^{\prime \prime} / f-\left(f^{\prime}\right)^{2} / f^{2}\right]}{\sqrt{\sigma_{D}^{2}+4 \theta\left(\mu_{H}-S\right)\left(S-\mu_{L}\right)\left(f^{\prime} / f\right)}} \\
\left(\sigma_{P}^{D}\right)^{\prime \prime}= & -\frac{2\left\{\theta\left(\mu_{H}+\mu_{L}-2 S\right)\left(f^{\prime} / f\right)+\theta\left(\mu_{H}-S\right)\left(S-\mu_{L}\right)\left[f^{\prime \prime} / f-\left(f^{\prime}\right)^{2} / f^{2}\right]\right\}^{2}}{\left[\sigma_{D}^{2}+4 \theta\left(\mu_{H}-S\right)\left(S-\mu_{L}\right)\left(f^{\prime} / f\right)\right]^{3 / 2}} \\
& +\frac{-2 \theta f^{\prime} / f+2 \theta\left(\mu_{H}+\mu_{L}-2 S\right)\left[f^{\prime \prime} / f-\left(f^{\prime}\right)^{2} / f^{2}\right]}{\sqrt{\sigma_{D}^{2}+4 \theta\left(\mu_{H}-S\right)\left(S-\mu_{L}\right)\left(f^{\prime} / f\right)}} \\
& +\frac{\theta\left(\mu_{H}-S\right)\left(S-\mu_{L}\right)\left[f^{\prime \prime \prime} / f-3\left(f^{\prime} f^{\prime \prime}\right) / f^{2}+2\left(f^{\prime}\right)^{3} / f^{3}\right]}{\sqrt{\sigma_{D}^{2}+4 \theta\left(\mu_{H}-S\right)\left(S-\mu_{L}\right)\left(f^{\prime} / f\right)}} .
\end{aligned}
$$




\section{Appendix C. Numerical procedure for solving the equilibrium}

Eqs. (A.5) and (A.9) can only be solved numerically. Specifically, we apply a projection method with Chebyshev polynomials. To start, we note that the value of the sentiment variable $S$ ranges from $\mu_{L}$ to $\mu_{H}$, whereas the domain for Chebyshev polynomials is $[-1,1]$. Therefore, we transform $S$ to a new state variable $z$

$$
z \equiv a S+b, \quad \text { where } a=\frac{2}{\mu_{H}-\mu_{L}}, b=-\frac{\mu_{H}+\mu_{L}}{\mu_{H}-\mu_{L}}
$$

and we define $h(z) \equiv f(S(z))$ and $j(z) \equiv l(S(z))$. Eqs. (A.5) and (A.9) can be rewritten as

$$
0=\left[\begin{array}{l}
-\frac{(1-\gamma)}{1-\psi} \delta-\gamma g_{C}^{e}+g_{D}^{e}+\left[\left(h^{\prime} / h\right)+\frac{\psi-\gamma}{1-\psi}\left(j^{\prime} / j\right)\right] a \mu_{S}^{e}+\frac{1}{2}\left[\left(h^{\prime \prime} / h\right)+\frac{\psi-\gamma}{1-\psi}\left(j^{\prime \prime} / j\right)\right] a^{2} \sigma_{S}^{2} \\
+\frac{\gamma(\gamma+1)}{2} \sigma_{C}^{2}+\frac{1}{2} \frac{\psi-\gamma}{1-\psi} \frac{2 \psi-\gamma-1}{1-\psi}\left(a j^{\prime} / j\right)^{2} \sigma_{S}^{2}-\frac{\gamma(\psi-\gamma)}{1-\psi} \rho \sigma_{C} \sigma_{S}\left(a j^{\prime} / j\right)-\gamma \rho \sigma_{C} \sigma_{D}-\gamma \rho \sigma_{C} \sigma_{S}\left(a h^{\prime} / h\right) \\
+\frac{\psi-\gamma}{1-\psi} \sigma_{D} \sigma_{S}\left(a j^{\prime} / j\right)+\frac{\psi-\gamma}{1-\psi} \sigma_{S}^{2} a^{2}\left(j^{\prime} / j\right)\left(h^{\prime} / h\right)+\sigma_{D} \sigma_{S}\left(a h^{\prime} / h\right)+\frac{\psi-\gamma}{1-\psi} j^{-1}+h^{-1}
\end{array}\right]
$$

and

$$
0=\left[\begin{array}{l}
-\frac{1-\gamma}{1-\psi} \delta-(\gamma-1) g_{C}^{e}+\frac{\gamma(\gamma-1)}{2} \sigma_{C}^{2}+\frac{1-\gamma}{1-\psi}\left(a j^{\prime} / j\right) \mu_{S}^{e}+\frac{1-\gamma}{2(1-\psi)}\left(a^{2} j^{\prime \prime} / j\right) \sigma_{S}^{2} \\
+\frac{1}{2} \frac{1-\gamma}{1-\psi} \frac{\psi-\gamma}{1-\psi}\left(a j^{\prime} / j\right)^{2} \sigma_{S}^{2}+\frac{(1-\gamma)^{2}}{1-\psi} \rho \sigma_{C} \sigma_{S}\left(a j^{\prime} / j\right)+\frac{1-\gamma}{1-\psi} j^{-1}
\end{array}\right]
$$

We approximate $h$ and $j$ by

$$
\hat{h}(z)=\sum_{r=0}^{n} a_{r} T_{r}(z), \quad \hat{l}(z)=\sum_{r=0}^{m} b_{r} T_{r}(z)
$$

where $T_{r}(z)$ is the $r^{t h}$ degree Chebyshev polynomial of the first kind. ${ }^{32}$ The projection method chooses the coefficients $\left\{a_{r}\right\}_{r=0}^{n}$ and $\left\{b_{r}\right\}_{r=0}^{m}$ so that the differential equations are approximately satisfied. One criterion for a sufficient approximation is to minimize the weighted sum of squared

\footnotetext{
${ }^{32}$ See Mason and Handscomb (2003) for a detailed discussion of the properties of Chebyshev polynomials.
} 
errors

$$
\begin{aligned}
& \sum_{i=1}^{N} \frac{1}{\sqrt{1-z_{i}^{2}}}\left[\begin{array}{l}
-\frac{(1-\gamma)}{1-\psi} \delta-\gamma g_{C}^{e}+g_{D}^{e}+\left[\left(\hat{h}^{\prime} / \hat{h}\right)+\frac{\psi-\gamma}{1-\psi}\left(\hat{j}^{\prime} / \hat{j}\right)\right] a \mu_{S}^{e}+\frac{1}{2}\left[\left(\hat{h}^{\prime \prime} / \hat{h}\right)+\frac{\psi-\gamma}{1-\psi}\left(\hat{j}^{\prime \prime} / \hat{j}\right)\right] a^{2} \sigma_{S}^{2} \\
+\frac{\gamma(\gamma+1)}{2} \sigma_{C}^{2}+\frac{1}{2} \frac{\psi-\gamma}{1-\psi} \frac{2 \psi-\gamma-1}{1-\psi}\left(a \hat{j}^{\prime} / \hat{j}\right)^{2} \sigma_{S}^{2}-\frac{\gamma(\psi-\gamma)}{1-\psi} \rho \sigma_{C} \sigma_{S}\left(a \hat{j}^{\prime} / \hat{j}\right)-\gamma \rho \sigma_{C} \sigma_{D} \\
-\gamma \rho \sigma_{C} \sigma_{S}\left(a \hat{h}^{\prime} / \hat{h}\right)+\frac{\psi-\gamma}{1-\psi} \sigma_{D} \sigma_{S}\left(a \hat{j}^{\prime} / \hat{j}\right)+\frac{\psi-\gamma}{1-\psi} \sigma_{S}^{2} a^{2}\left(\hat{j}^{\prime} / \hat{j}\right)\left(\hat{h}^{\prime} / \hat{h}\right)+\sigma_{D} \sigma_{S}\left(a \hat{h}^{\prime} / \hat{h}\right) \\
+\frac{\psi-\gamma}{1-\psi} \hat{j}^{-1}+\hat{h}^{-1}
\end{array}\right]_{z=z_{i}}^{2} \\
& +\sum_{i=1}^{N} \frac{1}{\sqrt{1-z_{i}^{2}}}\left[\begin{array}{l}
-\frac{1-\gamma}{1-\psi} \delta-(\gamma-1) g_{C}^{e}+\frac{\gamma(\gamma-1)}{2} \sigma_{C}^{2}+\frac{1-\gamma}{1-\psi}\left(a \hat{j}^{\prime} / \hat{j}\right) \mu_{S}^{e}+\frac{1-\gamma}{2(1-\psi)}\left(a^{2} \hat{j}^{\prime \prime} / \hat{j}\right) \sigma_{S}^{2} \\
+\frac{1}{2} \frac{1-\gamma}{1-\psi} \frac{\psi-\gamma}{1-\psi}\left(a \hat{j}^{\prime} / \hat{j}\right)^{2} \sigma_{S}^{2}+\frac{(1-\gamma)^{2}}{1-\psi} \rho \sigma_{C} \sigma_{S}\left(a \hat{j}^{\prime} / \hat{j}\right)+\frac{1-\gamma}{1-\psi} \hat{j}^{-1}
\end{array}\right]_{z=z_{i}}^{2}
\end{aligned}
$$

where $\left\{z_{i}\right\}_{i=1}^{N}$ are the $N$ zeros of $T_{N}(z)$. By the Chebyshev interpolation theorem, if $N$ is sufficiently larger than $n$ and $m$, and if the sum of weighted square in (C.5) is sufficiently small, the approximated functions $\hat{h}(z)$ and $\hat{l}(z)$ are sufficiently close to the true solutions.

For the numerical results in the main text, we set $m=40, n=40$, and $N=400$. We then apply the Levenberg-Marquardt algorithm and obtain a minimized sum of squared errors less than $10^{-12}$. The small size of the total error indicates convergence of the numerical solution. The solution is also insensitive to the choice of $n, m$, or $N$. Together, these findings suggest that the numerical solutions are a sufficient approximation for the true $h$ and $j$ functions.

The same numerical procedure is applied to solving the Kolmogorov forward equation (B.2). 


\section{Appendix D. Additional discussion about return expectations and cash-flow expectations}

The direct implication of return extrapolation is that the agent's subjective expectation about the future stock market return

$$
1+\mathbb{E}_{t}^{e}\left[\hat{r}_{t+d t}^{D}\right] d t=\mathbb{E}_{t}^{e}\left[\frac{P_{t+d t}^{D}}{P_{t}^{D}}\right]+\frac{D_{t} d t}{P_{t}^{D}}
$$

is a positive function of the stock market's recent past returns, where $\hat{r}_{t+d t}^{D} \equiv\left(R_{t+d t}^{D}-1\right) / d t$ is the rate of return of the stock market from $t$ to $t+d t$. Rearranging terms gives

$$
\frac{P_{t}^{D}}{D_{t}}=\frac{1}{\mathbb{E}_{t}^{e}\left[\hat{r}_{t+d t}^{D}\right]-\mathbb{E}_{t}^{e}\left[d P_{t}^{D} /\left(P_{t}^{D} d t\right)\right]}
$$

That is, the current price-dividend ratio is determined by the agent's subjective expectation about the future stock market return $\mathbb{E}_{t}^{e}\left[\hat{r}_{t+d t}^{D}\right]$ and the agent's subjective expectation about future price growth $\mathbb{E}_{t}^{e}\left[d P_{t}^{D} /\left(P_{t}^{D} d t\right)\right]$. Eq. (D.2) does not suggest an explicit role for the agent's expectation about dividend growth in determining the price-dividend ratio.

However, two conditions allow us to link the price-dividend ratio of the stock market to the agent's expectation about dividend growth. First, the law of iterated expectations must hold so that we can iterate forward the Euler equation (4) with the stock market as the tradeable asset. Second, the transversality condition must hold so that the economy permits no bubbles. ${ }^{33}$ These two conditions allow us to obtain

$$
\frac{P_{t}^{D}}{D_{t}}=\mathbb{E}_{t}^{e}\left[\int_{t}^{\infty} e^{-\delta(1-\gamma)(s-t) /(1-\psi)}\left(\frac{\tilde{C}_{s}}{C_{t}}\right)^{-\psi(1-\gamma) /(1-\psi)} \tilde{M}_{t \rightarrow s}^{(\psi-\gamma) /(1-\psi)}\left(\frac{\tilde{D}_{s}}{D_{t}}\right) d s\right]
$$

where $\tilde{M}_{t \rightarrow s}$ denotes the continuously compounded gross return for holding the Lucas tree from time $t$ to time $s(>t)$. Eq. (D.3) says that the current price-dividend ratio of the stock market equals the agent's subjective expectation of the sum of discounted future dividend growths.

For an infinitely lived agent, (D.3) further implies that the agent is aware of the fact that both her expectation about future price growth and her expectation about future returns are linked to

\footnotetext{
${ }^{33}$ The transversality condition holds in this economy as the stock market price is bounded by a finite range.
} 
her expectation about future dividend growth. The specific relation between these expectations is discussed in Sections 2 and 3. 


\section{Appendix E. Setup of the fundamental extrapolation model}

In this section, we briefly describe the fundamental extrapolation model that Section 4 discussed. In this model, the agent believes that the expected growth rate of dividends, instead of the expected growth rate of stock market prices in the case of return extrapolation, is governed by $(1-\theta) g_{D}+\theta \tilde{\mu}_{S, t}$, where $\tilde{\mu}_{S, t}$ is a latent variable that follows a regime-switching process described in Section 2. The agent does not directly observe the latent variable $\tilde{\mu}_{S, t}$. Instead, she computes its expected value given the history of past dividend growth: $S_{t} \equiv \mathbb{E}\left[\tilde{\mu}_{S, t} \mid \mathcal{F}_{t}^{D}\right]$. She then applies optimal filtering theory and derives

$$
\begin{aligned}
d S_{t} & =\chi\left[\left(\mu_{H}-S_{t}\right)+\left(\mu_{L}-S_{t}\right)\right] d t+\sigma_{D}^{-1} \theta\left(\mu_{H}-S_{t}\right)\left(S_{t}-\mu_{L}\right) d \omega_{t}^{e} \\
& \equiv \mu_{S}^{e}\left(S_{t}\right) d t+\sigma_{S}\left(S_{t}\right) d \omega_{t}^{e},
\end{aligned}
$$

where $d \omega_{t}^{e} \equiv\left[d D_{t} / D_{t}-(1-\theta) g_{D} d t-\theta S_{t} d t\right] / \sigma_{D}$ is a standard Brownian innovation term from the agent's perspective. That is, she perceives the evolution of dividend as

$$
d D_{t} / D_{t}=g_{D}^{e}\left(S_{t}\right) d t+\sigma_{D} d \omega_{t}^{e}
$$

where

$$
g_{D}^{e}\left(S_{t}\right)=(1-\theta) g_{D}+\theta S_{t}
$$

In other words, the agent's expectation about dividend growth $g_{D}^{e}\left(S_{t}\right)$ is a linear combination of a rational component $g_{D}$ and a sentiment component $S_{t}$ constructed from past dividend growth. On the other hand, the perceived evolution of the stock market price can be derived as

$$
d P_{t}^{D} / P_{t}^{D}=\mu_{P}^{D, e}\left(S_{t}\right) d t+\sigma_{P}^{D}\left(S_{t}\right) d \omega_{t}^{e},
$$

where

$$
\begin{aligned}
\mu_{P}^{D, e}(S) & =\left(f^{\prime} / f\right) \mu_{S}^{e}+\frac{1}{2}\left(f^{\prime \prime} / f\right) \sigma_{S}^{2}+(1-\theta) g_{D}+\theta S-\sigma_{D}^{2}+\sigma_{D} \sigma_{P}^{D}(S) \\
\sigma_{P}^{D}(S) & =\sigma_{D}+\left(f^{\prime} / f\right) \sigma_{D}^{-1} \theta\left(\mu_{H}-S\right)\left(S-\mu_{L}\right) .
\end{aligned}
$$


As before, $f$ is defined as the price-dividend ratio of the stock market.

As with the return extrapolation model, Eqs. (A.5) and (A.9) determine $f$ and $l$, the pricedividend ratio and the wealth-consumption ratio, except that $\mu_{S}, \sigma_{S}, g_{D}^{e}, \mu_{P}^{D, e}$, and $\sigma_{P}^{D}$ are now from (E.1), (E.3), and (E.5). 


\section{References}

Adam, K., Marcet, A., Beutel, J., 2017. Stock price booms and expected capital gains. American Economic Review 107, 2352-2408.

Alti, A., Tetlock, P., 2014. Biased beliefs, asset prices, and investment: A structural approach. Journal of Finance 69, 325-361.

Amromin, G., Sharpe, S. A., 2013. Expectation of risk and return among household investors: Are their Sharpe ratios countercyclical? Unpublished working paper, Federal Reserve Board, Washington DC.

Bacchetta, P., Mertens, E., van Wincoop, E., 2009. Predictability in financial markets: What do survey expectations tell us? Journal of International Money and Finance 28, 406-426.

Barberis, N., 2018. Psychology-based models of asset prices and trading volume. In: Bernheim, D., DellaVigna, S., Laibson, D. (Eds.), Handbook of Behavioral Economics, North Holland, Amsterdam, pp. 79-175.

Barberis, N., Greenwood, R., Jin, L., Shleifer, A., 2015. X-CAPM: An extrapolative capital asset pricing model. Journal of Financial Economics 115, 1-24.

Barberis, N., Greenwood, R., Jin, L., Shleifer, A., 2018. Extrapolation and bubbles. Journal of Financial Economics 129, 203-227.

Barberis, N., Huang, M., Santos, T., 2001. Prospect theory and asset prices. Quarterly Journal of Economics 116, 1-53.

Barberis, N., Shleifer, A., Vishny, R., 1998. A model of investor sentiment. Journal of Financial Economics 49, 307-343.

Baron, M., Xiong, W., 2017. Credit expansion and neglected crash risk. Quarterly Journal of Economics 132, 713-764.

Beeler, J., Campbell, J. Y., 2012. The long-run risks model and aggregate asset prices: An empirical assessment. Critical Finance Review 1, 141-182. 
Bordalo, P., Gennaioli, N., LaPorta, R., Shleifer, A., 2020. Expectations of fundamentals and stock market puzzles. Unpublished working paper, Harvard University.

Bordalo, P., Gennaioli, N., Shleifer, A., 2018. Diagnostic expectations and credit cycles. Journal of Finance 73, 199-227.

Borovicka, J., 2020. Survival and long-run dynamics with heterogeneous beliefs under recursive preferences. Journal of Political Economy 128, 206-251.

Campbell, J. Y., 2003. Consumption-based asset pricing. In: Constantinides, G. M., Harris, M., Stulz, R. M. (Eds.), Handbook of the Economics of Finance, Elsevier, Amsterdam, pp. 801-885.

Campbell, J. Y., Cochrane, J., 1999. By force of habit: A consumption-based explanation of aggregate stock market behavior. Journal of Political Economy 107, 205-251.

Campbell, J. Y., Shiller, R., 1988. The dividend-price ratio and expectations of future dividends and discount factors. Review of Financial Studies 1, 195-228.

Cassella, S., Gulen, H., 2018. Extrapolation bias and the predictability of stock returns by pricescaled variables. Review of Financial Studies 31, 4345-4397.

Choi, J., Mertens, T., 2013. Extrapolative expectations and the equity premium. Unpublished working paper, Yale University.

Cochrane, J. H., 2011. Presidential address: Discount rates. Journal of Finance 66, 1047-1108.

Cutler, D. M., Poterba, J. M., Summers, L. H., 1990. Speculative dynamics and the role of feedback traders. American Economic Review 80, 63-68.

Da, Z., Huang, X., Jin, L. J., 2021. Extrapolative beliefs in the cross-section: What can we learn from the crowds? Journal of Financial Economics 140, 175-196.

Daniel, K., Hirshleifer, D., Subrahmanyam, A., 1998. Investor psychology and security market under- and overreactions. Journal of Finance 53, 1839-1885.

Daniel, K., Klos, A., Rottke, S., 2021. The dynamics of disagreement. Unpublished working paper, Columbia University. 
De la O, R., Myers, S., 2021. Subjective cash flow and discount rate expectations. Journal of Finance 76, 1339-1387.

De Long, B., Shleifer, A., Summers, L., Waldmann, R., 1990. Positive feedback investment strategies and destablizing rational speculation. Journal of Finance 45, 379-395.

Ehling, P., Graniero, A., Heyerdahl-Larsen, C., 2018. Asset prices and portfolio choice with learning from experience. Review of Economic Studies 85, 1752-1780.

Epstein, L., Zin, S., 1989. Substitution, risk aversion, and the temporal behavior of consumption and asset returns: A theoretical framework. Econometrica 57, 937-969.

Epstein, L., Zin, S., 1991. Substitution, risk aversion, and the temporal behavior of consumption and asset returns: An empirical analysis. Journal of Political Economy 99, 263-286.

Fama, E., French, K., 1988. Dividend yields and expected stock returns. Journal of Financial Economics 22, 3-25.

Fuster, A., Hebert, B., Laibson, D., 2011. Natural expectations, macroeconomic dynamics, and asset pricing. NBER Macroeconomics Annual 26, 1-48.

Greenwood, R., Hanson, S. G., 2013. Issuer quality and corporate bond returns. Review of Financial Studies 26, 1483-1525.

Greenwood, R., Shleifer, A., 2014. Expectations of returns and expected returns. Review of Financial Studies 27, 714-746.

Hansen, L., Singleton, K., 1982. Generalized instrumental variables estimation of nonlinear rational expectations models. Econometrica 50, 1269-1286.

Hansen, L., Singleton, K., 1983. Stochastic consumption, risk aversion, and the temporal behavior of asset returns. Journal of Political Economy 91, 249-265.

Hartzmark, S. M., Solomon, D. H., 2021. Reconsidering returns. Review of Financial Studies Forthcoming.

Hirshleifer, D., Li, J., Yu, J., 2015. Asset pricing in production economies with extrapolative expectations. Journal of Monetary Economics 76, 87-106. 
Hong, H., Stein, J. C., 1999. A unified theory of underreaction, momentum trading, and overreaction in asset markets. Journal of Finance 54, 2143-2184.

Huang, X., 2019. Mark Twain's cat: Investment experience, categorical thinking, and stock selection. Journal of Financial Economics 131, 404-432.

Jin, L. J., 2015. A speculative asset pricing model of financial instability. Unpublished working paper, California Institute of Technology.

Kahneman, D., Tversky, A., 1979. Prospect theory: An analysis of decision under risk. Econometrica $47,263-292$.

Kuchler, T., Zafar, B., 2019. Personal experiences and expectations about aggregate outcomes. Journal of Finance 74, 2491-2542.

Li, K., Liu, J., 2020. Extrapolative asset pricing. Unpublished working paper, University of California, San Diego.

Liao, J., Peng, C., Zhu, N., 2021. Extrapolative bubbles and trading volume. Review of Financial Studies Forthcoming.

Lipster, R., Shiryaev, A., 2001. Statistics of Random Processes I, General Theory. Springer, New York.

Malmendier, U., Nagel, S., 2011. Depression babies: Do macroeconomic experiences affect risktaking? Quarterly Journal of Economics 126, 373-416.

Mason, J. C., Handscomb, D. C., 2003. Chebyshev Polynomials. Chapman \& Hall/CRC, New York.

Mehra, R., Prescott, E. C., 1985. The equity premium: A puzzle. Journal of Monetary Economics $15,145-161$.

Nagel, S., Xu, Z., 2021. Asset pricing with fading memory. Review of Financial Studies Forthcoming.

Tversky, A., Kahneman, D., 1974. Judgment under uncertainty: Heuristics and biases. Science 185, $1124-1131$. 
Veronesi, P., 1999. Stock market overreaction to bad news in good times: A rational expectations equilibrium model. Review of Financial Studies 12, 975-1007.

Vissing-Jorgensen, A., 2004. Perspectives on behavioral finance: Does "irrationality" disappear with wealth? Evidence from expectations and actions. NBER Macroeconomics Annual 2003 18, $139-194$.

Wachter, J. A., Kahana, M. J., 2020. Associative learning and representativeness. Unpublished working paper, University of Pennsylvania.

Wachter, J. A., Kahana, M. J., 2021. A retrieved-context theory of financial decisions. Unpublished working paper, University of Pennsylvania.

Xiong, W., 2013. Bubbles, crises, and heterogeneous beliefs. In: Fouque, J.-P., Langsam, J. A. (Eds.), Handbook on Systemic Risk, Cambridge University Press, Cambridge, pp. 663-713.

Yu, J., 2012. Using long-run consumption-return correlations to test asset pricing models. Review of Economic Dynamics 15, 317-335. 


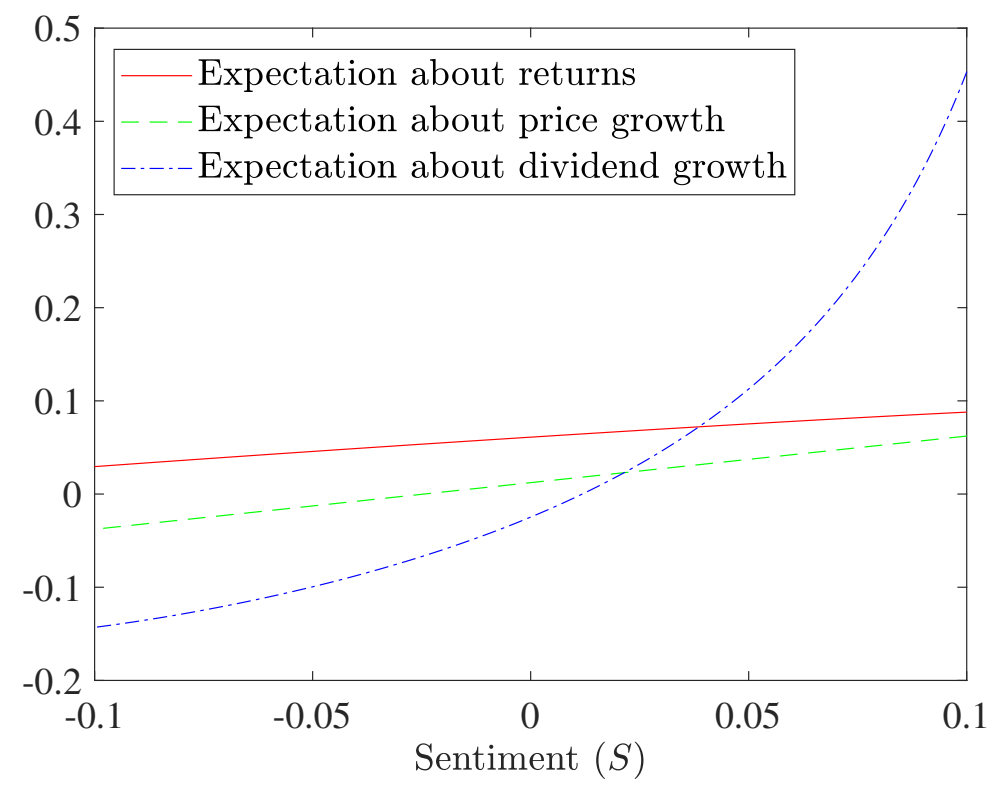

Fig. 1. Agent's expectations about stock market returns, price growth, and dividend growth. The solid line plots the agent's expectation about stock market returns, $\mathbb{E}_{t}^{e}\left[\left(d P_{t}^{D}+D_{t} d t\right) /\left(P_{t}^{D} d t\right)\right]$, as a function of the sentiment variable $S_{t}$. The dashed line plots the agent's expectation about price growth, $\mathbb{E}_{t}^{e}\left[d P_{t}^{D} /\left(P_{t}^{D} d t\right)\right]$, as a function of the sentiment variable $S_{t}$. The dash-dot line plots the agent's expectation about dividend growth, $\mathbb{E}_{t}^{e}\left[d D_{t} /\left(D_{t} d t\right)\right]$, as a function of the sentiment variable $S_{t}$. The parameter values are: $g_{C}=1.91 \%, g_{D}=2.45 \%, \sigma_{C}=3.8 \%, \sigma_{D}=11 \%, \rho=0.2, \gamma=10$, $\psi=0.9, \delta=2 \%, \theta=0.5, \chi=0.2, \mu_{H}=12.5 \%$, and $\mu_{L}=-12.5 \%$. 

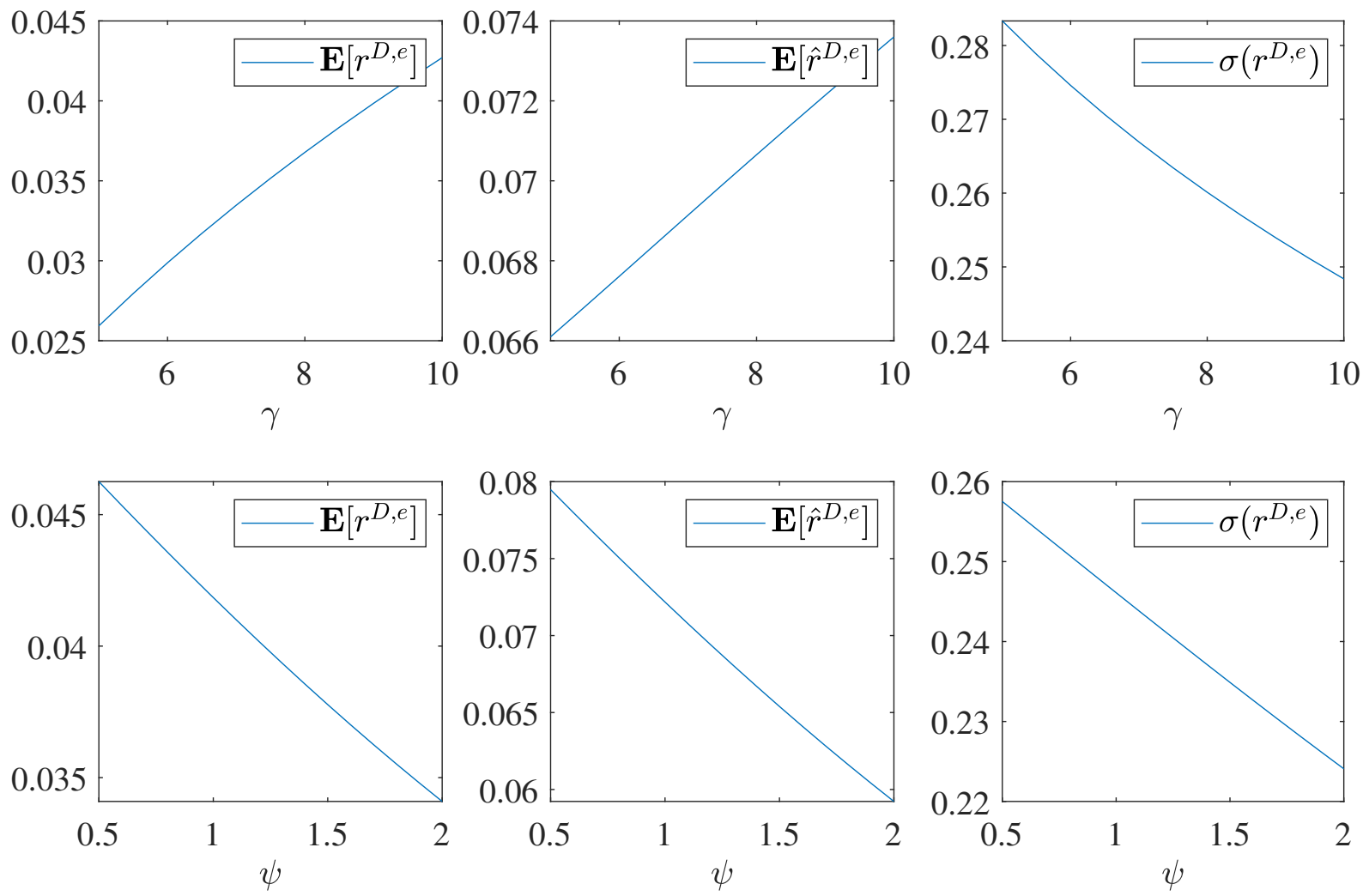

Fig. 2. Comparative statics. The upper panel plots the average log excess return $\mathbb{E}\left[r^{D, e}\right]$, the average excess return $\mathbb{E}\left[\hat{r}^{D, e}\right]$, and the average volatility of log excess returns $\sigma\left(r^{D, e}\right)$, each as a function of $\gamma$, the coefficient of relative risk aversion. The lower panel plots the same quantities, each as a function of $\psi$, the reciprocal of the elasticity of intertemporal substitution. The default values for $\gamma$ and $\psi$ are 10 and 0.9 , respectively. The other parameter values are: $g_{C}=1.91 \%, g_{D}=$ $2.45 \%, \sigma_{C}=3.8 \%, \sigma_{D}=11 \%, \rho=0.2, \delta=2 \%, \theta=0.5, \chi=0.2, \mu_{H}=12.5 \%$, and $\mu_{L}=-12.5 \%$. 


\section{Table 1}

\section{Return expectations.}

The table reports the regression coefficient and the $t$-statistic (in parentheses), the intercept, and the $R$-squared, estimated from

$$
\mathbb{E}_{t}^{e}\left[\left(d P_{t}^{D}+D_{t} d t\right) /\left(P_{t}^{D} d t\right)\right]=a+b \cdot R_{t-12 \rightarrow t}^{D}+\varepsilon_{t},
$$

over a sample of 15 or 50 years. Each reported value is averaged over 100 trials, and each trial represents a regression using monthly data simulated from the model. The $t$-statistics are calculated using a Newey-West estimator with 12 -month lags. The parameter values are: $g_{C}=1.91 \%, g_{D}=2.45 \%, \sigma_{C}=3.8 \%, \sigma_{D}=11 \%, \rho=0.2, \gamma=10, \psi=$ $0.9, \delta=2 \%, \theta=0.5, \chi=0.2, \mu_{H}=12.5 \%$, and $\mu_{L}=-12.5 \%$.

\begin{tabular}{ccc} 
& $15 \mathrm{yr}$. & $50 \mathrm{yr}$. \\
$b$ & 0.02 & 0.02 \\
\multirow{2}{*}{$a$} & $(8.6)$ & $(12.4)$ \\
$R$-squared & 0.04 & 0.04 \\
\hline
\end{tabular}




\section{Table 2}

Determinants of return expectations.

The table reports the parameter $\phi$, the intercept $a$, the regression coefficient $b$, and the $R$-squared, estimated from the nonlinear least squares regression

$$
\mathbb{E}_{t}^{e}\left[\left(d P_{t}^{D}+D_{t} d t\right) /\left(P_{t}^{D} d t\right)\right]=a+b \cdot \sum_{j=1}^{n} w_{j}(\phi) R_{(t-j \Delta t) \rightarrow(t-(j-1) \Delta t)}^{D}+\varepsilon_{t},
$$

where $w_{j}(\phi)=\phi^{j} / \sum_{l=1}^{n} \phi^{l}, R_{(t-j \Delta t) \rightarrow(t-(j-1) \Delta t)}^{D}$ is the past stock market return from time $t-j \Delta t$ to $t-(j-1) \Delta t$, $\Delta t=1 / 4$ (one quarter), and $n=200$ (50 years). Each reported value is averaged over 100 trials, and each trial represents a regression using monthly data simulated from the model over 10,000 years. The parameter values are: $g_{C}=1.91 \%, g_{D}=2.45 \%, \sigma_{C}=3.8 \%, \sigma_{D}=11 \%, \rho=0.2, \gamma=10, \psi=0.9, \delta=2 \%, \theta=0.5, \chi=0.2, \mu_{H}=12.5 \%$, and $\mu_{L}=-12.5 \%$.

\begin{tabular}{cc} 
& $\theta=0.5, \chi=0.2$ \\
\cline { 2 - 2 }$\phi$ & 0.89 \\
$a$ & -0.25 \\
$b$ & 0.31 \\
$R$-squared & 0.96 \\
\hline
\end{tabular}


Table 3

Parameter values.

\begin{tabular}{lcc} 
Parameter & Variable & Value \\
\hline Asset parameters: & & \\
Expected consumption growth & $g_{C}$ & $1.91 \%$ \\
Expected dividend growth & $g_{D}$ & $2.45 \%$ \\
Standard deviation of consumption growth & $\sigma_{C}$ & $3.8 \%$ \\
Standard deviation of dividend growth & $\sigma_{D}$ & $11 \%$ \\
Correlation between $d D$ and $d C$ & $\rho$ & 0.2 \\
\hline Utility parameters: & & \\
Relative risk aversion & $\gamma$ & 10 \\
Reciprocal of $E I S$ & $\psi$ & 0.9 \\
Subjective discount rate & $\delta$ & 0.02 \\
\hline Belief parameters: & & \\
Degree of extrapolation & $\theta$ & 0.5 \\
Perceived transition intensity between $H$ and $L$ & $\chi$ & 0.2 \\
Upper bound of sentiment & $\mu_{H}$ & $12.5 \%$ \\
Lower bound of sentiment & $\mu_{L}$ & $-12.5 \%$ \\
\hline
\end{tabular}




\section{Table 4}

Basic moments.

The table reports six important moments about stock market prices and returns: the long-run average of the equity premium (the rational expectation of log excess returns, $\mathbb{E}\left[r^{D, e}\right]$ ), the average volatility of stock market returns (the volatility of $\log$ excess returns, $\left.\sigma\left(r^{D, e}\right)\right)$, the Sharpe ratio $\left(\mathbb{E}\left[r^{D, e}\right] / \sigma\left(r^{D, e}\right)\right)$, the average interest rate $(\mathbb{E}[r])$, interest rate volatility $(\sigma(r))$, and the average price-dividend ratio of the stock market $(\exp (\mathbb{E}[\ln (P / D)]))$. The theoretical values for these moments are computed over the objectively measured steady-state distribution of sentiment $S$. The model parameters are: $g_{C}=1.91 \%, g_{D}=2.45 \%, \sigma_{C}=3.8 \%, \sigma_{D}=11 \%, \rho=0.2, \gamma=10, \psi=0.9, \delta=2 \%, \theta=0.5$, $\chi=0.2, \mu_{H}=12.5 \%$, and $\mu_{L}=-12.5 \%$. For the empirical values, five out of six are from Campbell and Cochrane (1999); the empirical value for interest rate volatility is not reported in Campbell and Cochrane (1999), so we report the value from Beeler and Campbell (2012).

\begin{tabular}{ccc} 
Statistic & Theoretical value & Empirical value \\
\hline Equity premium $\left(\mathbb{E}\left[r^{D, e}\right]\right)$ & $4.27 \%$ & $3.90 \%$ \\
Return volatility $\left(\sigma\left(r^{D, e}\right)\right)$ & $24.8 \%$ & $18.0 \%$ \\
Sharpe ratio $\left(\mathbb{E}\left[r^{D, e}\right] / \sigma\left(r^{D, e}\right)\right)$ & 0.19 & 0.22 \\
Interest rate $(\mathbb{E}[r])$ & $2.17 \%$ & $2.92 \%$ \\
Interest rate volatility $(\sigma(r))$ & $0.30 \%$ & $2.89 \%$ \\
Price-dividend ratio $(\exp (\mathbb{E}[\ln (P / D)]))$ & 21.8 & 21.1 \\
\hline
\end{tabular}


Table 5

Return predictability regressions.

The table reports the regression coefficient $\beta_{j}$ and the $R$-squared for a regression of the log excess return of the stock market from time $t$ to time $t+j$ on the current $\log$ price-dividend ratio $\ln \left(P_{t}^{D} / D_{t}\right)$

$$
r_{t \rightarrow t+j}^{D, e}=\alpha_{j}+\beta_{j} \ell \mathrm{n}\left(P_{t}^{D} / D_{t}\right)+\varepsilon_{j, t}
$$

where $j=1,2,3,5$, and 7 (years). The theoretical values are calculated using 10,000 years of monthly data simulated from the model. The parameter values are: $g_{C}=1.91 \%, g_{D}=2.45 \%, \sigma_{C}=3.8 \%, \sigma_{D}=11 \%, \rho=0.2, \gamma=10$, $\psi=0.9, \delta=2 \%, \theta=0.5, \chi=0.2, \mu_{H}=12.5 \%$, and $\mu_{L}=-12.5 \%$. The empirical values are from Campbell and Cochrane (1999).

\begin{tabular}{cccccc} 
& \multicolumn{2}{c}{ Theoretical value } & & \multicolumn{2}{c}{ Empirical value } \\
\cline { 2 - 3 } \cline { 5 - 6 } Horizon (years) & $\begin{array}{c}10 \times \\
\text { coefficient }\end{array}$ & $R$-squared & & $\begin{array}{c}10 \times \\
\text { coefficient }\end{array}$ & $R$-squared \\
\hline 1 & -7.1 & 0.11 & & -1.3 & 0.04 \\
2 & -9.4 & 0.13 & & -2.8 & 0.08 \\
3 & -10.0 & 0.12 & & -3.5 & 0.09 \\
5 & -10.6 & 0.11 & & -6.0 & 0.18 \\
7 & -11.0 & 0.10 & & -7.5 & 0.23 \\
\hline
\end{tabular}


Table 6

Autocorrelations of log price-dividend ratios and log excess returns.

The table reports, over various lags $j$, the autocorrelations of log price-dividend ratios and log excess returns, as well as the partial sum of the autocorrelations of log excess returns. The operator $\rho(x, y)$ computes the sample correlation between variable $x$ and variable $y$. The theoretical values are calculated using 10,000 years of monthly data simulated from the model; for each month, we compound the next 12 months of log excess returns to obtain an annual log excess return. The parameter values are: $g_{C}=1.91 \%, g_{D}=2.45 \%, \sigma_{C}=3.8 \%, \sigma_{D}=11 \%, \rho=0.2, \gamma=10, \psi=0.9$, $\delta=2 \%, \theta=0.5, \chi=0.2, \mu_{H}=12.5 \%$, and $\mu_{L}=-12.5 \%$. The empirical values are from Campbell and Cochrane (1999).

\begin{tabular}{cccccccc}
\multirow{2}{*}{$\begin{array}{c}\text { Lag } \\
\text { (years })\end{array}$} & \multicolumn{3}{c}{ Theoretical value } & & \multicolumn{3}{c}{ Empirical value } \\
\cline { 2 - 4 } \cline { 6 - 8 } & $\ell \mathrm{n}\left(P^{D} / D\right)$ & $r^{D, e}$ & $\Sigma_{i=1}^{j} \rho\left(r_{t}^{D, e}, r_{t-i}^{D, e}\right)$ & & $\ln \left(P^{D} / D\right)$ & $r^{D, e}$ & $\Sigma_{i=1}^{j} \rho\left(r_{t}^{D, e}, r_{t-i}^{D, e}\right)$ \\
\hline 1 & 0.34 & -0.26 & -0.26 & & 0.78 & 0.05 & 0.05 \\
2 & 0.12 & -0.09 & -0.35 & & 0.57 & -0.21 & -0.16 \\
3 & 0.05 & -0.02 & -0.37 & & 0.50 & 0.08 & -0.09 \\
5 & 0.00 & -0.01 & -0.38 & & 0.32 & -0.14 & -0.28 \\
7 & -0.02 & -0.01 & -0.39 & & 0.29 & 0.11 & -0.15 \\
\hline
\end{tabular}




\section{Table 7}

\section{Dividend growth expectations and return expectations.}

The table reports the regression coefficient and the $t$-statistic (in parentheses), the intercept, the number of observations, and the $R$-squared, estimated from a regression of investor expectations - either about future dividend growth or about future returns - on investor sentiment, proxied either by the stock market's past 12-month cumulative return or by the model-implied sentiment measure $S_{t}$, constructed from Eq. (7). For the measure of dividend growth expectations, we use data from De la O and Myers (2021), namely, time-series data of investors' dividend growth expectations, aggregated from analyst forecasts of dividends of individual firms in the S\&P 500. These dividend forecasts are from the Thomson Reuters Institutional Brokers Estimate System (I/B/E/S). For measures of return expectations, we use data from Cassella and Gulen (2018), namely, time-series data of investors' return expectations from the Gallup survey, the American Association of Individual Investors survey (AA), and the Investors' Intelligence newsletter expectations survey (II). The $t$-statistics are calculated using a Newey-West estimator with 12 -month lags.

\begin{tabular}{|c|c|c|c|c|c|c|c|c|}
\hline & \multicolumn{2}{|c|}{ Dividend growth expectations } & \multicolumn{6}{|c|}{ Return expectations } \\
\hline & \multicolumn{2}{|c|}{$\mathrm{I} / \mathrm{B} / \mathrm{E} / \mathrm{S}$} & \multicolumn{2}{|c|}{ Gallup } & \multicolumn{2}{|c|}{ AA } & \multicolumn{2}{|c|}{ II } \\
\hline \multirow{2}{*}{$S_{t}$} & 1.49 & & 0.93 & & 0.28 & & 0.57 & \\
\hline & $(0.99)$ & & $(18.88)$ & & $(4.64)$ & & $(4.76)$ & \\
\hline \multirow{2}{*}{$R_{t-12 \rightarrow t}^{D}$} & & 0.21 & & 0.12 & & 0.03 & & 0.08 \\
\hline & & $(2.35)$ & & $(8.79)$ & & $(4.11)$ & & $(6.17)$ \\
\hline Constant & 0.11 & -0.11 & 0.09 & -0.02 & 0.09 & 0.06 & 0.09 & 0.01 \\
\hline Observations & 51 & 51 & 135 & 135 & 331 & 331 & 626 & 626 \\
\hline$R$-squared & 0.08 & 0.15 & 0.66 & 0.61 & 0.12 & 0.13 & 0.12 & 0.19 \\
\hline
\end{tabular}




\section{Table 8}

\section{Campbell-Shiller decomposition.}

The table reports the four coefficients, $D R_{\text {objective }}, C F_{\text {objective }}, D R_{\text {subjective }}$, and $C F_{\text {subjective }}$, defined in Eqs. (31) and (32) of the main text, as well as their corresponding $R$-squared. These coefficients and $R$-squared are calculated using 10,000 years of monthly data simulated from the model. For realized dividend growth and returns, $\sum_{j=0}^{\infty} \xi^{j} \Delta d_{(t+j \Delta t) \rightarrow(t+(j+1) \Delta t)}$ and $\sum_{j=0}^{\infty} \xi^{j} r_{(t+j \Delta t) \rightarrow(t+(j+1) \Delta t)}^{D}$ in (31) are approximated using 100 years of monthly simulated data. At each point in time, for a given level of sentiment, subjective expectations about dividend growth and returns in (32) are calculated as the average values of 100 trials. Each trial is 100 years of monthly simulated data under the agent's expectations with the given initial level of sentiment. From the simulated data, $\xi=0.9962$. The other parameter values are: $g_{C}=1.91 \%, g_{D}=2.45 \%, \sigma_{C}=3.8 \%, \sigma_{D}=11 \%, \rho=0.2, \gamma=10, \psi=0.9, \delta=$ $2 \%, \theta=0.5, \chi=0.2, \mu_{H}=12.5 \%$, and $\mu_{L}=-12.5 \%$.

\begin{tabular}{ccc} 
& \multicolumn{2}{c}{ Realized dividend growth and returns } \\
\cline { 2 - 3 } Coefficient & Value & $R$-squared \\
\hline$D R_{\text {objective }}$ & 0.96 & 0.06 \\
$C F_{\text {objective }}$ & 0.04 & $1.1 \times 10^{-4}$ \\
\hline
\end{tabular}

\begin{tabular}{ccc} 
& \multicolumn{2}{c}{ Subjective expectations about dividend growth and returns } \\
\cline { 2 - 3 } Coefficient & Value & $R$-squared \\
\hline$D R_{\text {subjective }}$ & -0.10 & 0.98 \\
$C F_{\text {subjective }}$ & 1.10 & 0.98 \\
\hline
\end{tabular}




\section{Table 9}

Autocorrelations of log price-dividend ratios and log excess returns $(\chi=0.02)$.

The table reports, over various lags $j$, the autocorrelations of log price-dividend ratios and log excess returns, as well as the partial sum of the autocorrelations of log excess returns. The operator $\rho(x, y)$ computes the sample correlation between variable $x$ and variable $y$. The theoretical values are calculated using 10,000 years of monthly data simulated from the model; for each month, we compound the next 12 months of log excess returns to obtain an annual log excess return. The parameter values are: $g_{C}=1.91 \%, g_{D}=2.45 \%, \sigma_{C}=3.8 \%, \sigma_{D}=11 \%, \rho=0.2, \gamma=10, \psi=0.9$, $\delta=2 \%, \theta=0.5, \chi=0.02, \mu_{H}=12.5 \%$, and $\mu_{L}=-12.5 \%$. The empirical values are from Campbell and Cochrane (1999).

\begin{tabular}{cccccccc}
\multirow{2}{*}{$\begin{array}{c}\text { Lag } \\
\text { years })\end{array}$} & \multicolumn{3}{c}{ Theoretical value } & & \multicolumn{3}{c}{ Empirical value } \\
\cline { 2 - 4 } \cline { 6 - 7 } & $\ell \mathrm{n}\left(P^{D} / D\right)$ & $r^{D, e}$ & $\sum_{i=1}^{j} \rho\left(r_{t}^{D, e}, r_{t-i}^{D, e}\right)$ & & $\ln \left(P^{D} / D\right)$ & $r^{D, e}$ & $\sum_{i=1}^{j} \rho\left(r_{t}^{D, e}, r_{t-i}^{D, e}\right)$ \\
\hline 1 & 0.77 & -0.11 & -0.11 & & 0.78 & 0.05 & 0.05 \\
2 & 0.60 & -0.08 & -0.20 & & 0.57 & -0.21 & -0.16 \\
3 & 0.47 & -0.05 & -0.24 & & 0.50 & 0.08 & -0.09 \\
5 & 0.28 & -0.04 & -0.32 & & 0.32 & -0.14 & -0.28 \\
7 & 0.16 & -0.03 & -0.38 & & 0.29 & 0.11 & -0.15 \\
\hline
\end{tabular}


Table 10

Return predictability regressions $(\chi=0.02)$.

The table reports the regression coefficient $\beta_{j}$ and the $R$-squared for a regression of the log excess return of the stock market from time $t$ to time $t+j$ on the current $\log$ price-dividend ratio $\ln \left(P_{t}^{D} / D_{t}\right)$

$$
r_{t \rightarrow t+j}^{D, e}=\alpha_{j}+\beta_{j} \ln \left(P_{t}^{D} / D_{t}\right)+\varepsilon_{j, t},
$$

where $j=1,2,3,5$, and 7 (years). The theoretical values are calculated using 10,000 years of monthly data simulated from the model. The parameter values are: $g_{C}=1.91 \%, g_{D}=2.45 \%, \sigma_{C}=3.8 \%, \sigma_{D}=11 \%, \rho=0.2, \gamma=10, \psi$ $=0.9, \delta=2 \%, \theta=0.5, \chi=0.02, \mu_{H}=12.5 \%$, and $\mu_{L}=-12.5 \%$. The empirical values are from Campbell and Cochrane (1999).

\begin{tabular}{ccccc} 
& \multicolumn{2}{c}{ Theoretical value } & & \multicolumn{2}{c}{ Empirical value } \\
\cline { 2 - 3 } Horizon (years) & $\begin{array}{c}10 \times \\
\text { coefficient }\end{array}$ & $R$-squared & & $\begin{array}{c}10 \times \\
\text { coefficient }\end{array}$ \\
\hline 1 & -2.7 & 0.06 & -1.3 & 0.04 \\
2 & -4.7 & 0.10 & -2.8 & 0.08 \\
3 & -6.3 & 0.13 & -3.5 & 0.09 \\
5 & -8.6 & 0.18 & -6.0 & 0.18 \\
7 & -10.1 & 0.20 & -7.5 & 0.23 \\
\hline
\end{tabular}




\section{Table 11}

Model comparison.

Panel A reports the regression coefficient and the $t$-statistic (in parentheses), the intercept, and the $R$-squared, estimated from

$$
\mathbb{E}_{t}^{e}\left[\left(d P_{t}^{D}+D_{t} d t\right) /\left(P_{t}^{D} d t\right)\right]=a+b \cdot R_{t-12 \rightarrow t}^{D}+\varepsilon_{t},
$$

over a sample of 15 or 50 years. Each reported value is averaged over 100 trials, and each trial represents a regression using monthly data simulated from the fundamental extrapolation model described in Section 4.3 and Appendix E. Panel B reports the regression coefficient and the $t$-statistic (in parentheses), the intercept, and the $R$-squared, estimated from

$$
\mathbb{E}_{t}^{e}\left[\left(d D_{t}\right) /\left(D_{t} d t\right)\right]=a+b \cdot\left(D_{t} / D_{t-12}-1\right)+\varepsilon_{t},
$$

over a sample of 15 or 50 years. Here the dependent variable is the agent's time- $t$ expectation about dividend growth, and the independent variable is the realized dividend growth over the past 12 months. Each reported value is averaged over 100 trials, and each trial represents a regression using monthly data simulated from the return extrapolation model described in Section 2. For both panels, the $t$-statistics are calculated using a Newey-West estimator with 12-month lags. The parameter values are: $g_{C}=1.91 \%, g_{D}=2.45 \%, \sigma_{C}=3.8 \%, \sigma_{D}=11 \%, \rho=0.2, \gamma=10, \psi=$ $0.9, \delta=2 \%, \theta=0.5, \chi=0.2, \mu_{H}=12.5 \%$, and $\mu_{L}=-12.5 \%$.

Panel A: Return expectations in the fundamental extrapolation model

\begin{tabular}{ccc}
\hline & $15 \mathrm{yr}$. & $50 \mathrm{yr}$. \\
\cline { 2 - 3 }$b$ & 0.002 & 0.001 \\
& $(0.009)$ & $(0.052)$ \\
$a$ & 0.04 & 0.04 \\
$R$-squared & 0.09 & 0.04 \\
\hline
\end{tabular}

Panel B: Dividend growth expectations in the return extrapolation model

\begin{tabular}{ccc}
\hline & $15 \mathrm{yr}$. & $50 \mathrm{yr}$. \\
\cline { 2 - 3 }$b$ & 0.38 & 0.40 \\
$a$ & $(16.6)$ & $(26.2)$ \\
$R$-squared & -0.001 & -0.001 \\
\hline
\end{tabular}


Table 12

Return predictability regressions in the true regime-switching model.

The table reports the regression coefficient $\beta_{j}$ and the $R$-squared for a regression of the log excess return of the stock market from time $t$ to time $t+j$ on the current $\log$ price-dividend ratio $\ln \left(P_{t}^{D} / D_{t}\right)$

$$
r_{t \rightarrow t+j}^{D, e}=\alpha_{j}+\beta_{j} \ell \mathrm{n}\left(P_{t}^{D} / D_{t}\right)+\varepsilon_{j, t}
$$

where $j=1,2,3,5$, and 7 (years). The theoretical values are calculated using 10,000 years of monthly data simulated from the true regime-switching model described in Section 4. The parameter values are: $g_{C}=1.91 \%, g_{D}=2.45 \%$, $\sigma_{C}=3.8 \%, \sigma_{D}=11 \%, \rho=0.2, \gamma=10, \psi=0.9, \delta=2 \%, \theta=0.5, \chi=0.2, \mu_{H}=12.5 \%$, and $\mu_{L}=-12.5 \%$. The empirical values are from Campbell and Cochrane (1999).

\begin{tabular}{cccccc} 
& \multicolumn{2}{c}{ Theoretical value } & & \multicolumn{2}{c}{ Empirical value } \\
\cline { 2 - 3 } \cline { 5 - 5 } Horizon (years) & $\begin{array}{c}10 \times \\
\text { coefficient }\end{array}$ & $\begin{array}{c}10^{2} \times \\
R \text {-squared }\end{array}$ & & $\begin{array}{c}10 \times \\
\text { coefficient }\end{array}$ & $R$-squared \\
\hline 1 & 0.3 & 0.03 & -1.3 & 0.04 \\
2 & 0.5 & 0.05 & -2.8 & 0.08 \\
3 & 0.7 & 0.07 & -3.5 & 0.09 \\
5 & 1.1 & 0.09 & & -6.0 & 0.18 \\
7 & 1.5 & 0.12 & -7.5 & 0.23 \\
\hline
\end{tabular}

